\title{
Effect of Inductive Coil Geometry on the Operating Characteristics of an Inductive Pulsed Plasma Thruster
}

\author{
Ashley K. Hallock* \\ Yetispace Inc., Huntsville, AL 35802 USA
}

\author{
Kurt A. Polzin,$^{\dagger}$ Adam C. Kimberlin, ${ }^{\ddagger}$ and Kevin A. Perdue ${ }^{\S}$ \\ NASA - Marshall Space Flight Center, Huntsville, AL 35812 USA
}

\begin{abstract}
Operational characteristics of two separate inductive thrusters with conical theta pinch coils of different cone angles are explored through thrust stand measurements and timeintegrated, unfiltered photography. Trends in impulse bit measurements indicate that, in the present experimental configuration, the thruster with the inductive coil possessing a smaller cone angle produced larger values of thrust, in apparent contradiction to results of a previous thruster acceleration model. Areas of greater light intensity in photographs of thruster operation are assumed to qualitatively represent locations of increased current density. Light intensity is generally greater in images of the thruster with the smaller cone angle when compared to those of the thruster with the larger half cone angle for the same operating conditions. The intensity generally decreases in both thrusters for decreasing mass flow rate and capacitor voltage. The location of brightest light intensity shifts upstream for decreasing mass flow rate of propellant and downstream for decreasing applied voltage. Recognizing that there typically exists an optimum ratio of applied electric field to gas pressure with respect to breakdown efficiency, this result may indicate that the optimum ratio was not achieved uniformly over the coil face, leading to non-uniform and incomplete current sheet formation in violation of the model assumption of immediate formation where all the injected propellant is contained in a magnetically-impermeable current sheet.
\end{abstract}

\section{Introduction}

$\mathrm{T}^{\mathrm{T}}$ is desirable to extend the lifetime and increase the reliability of a spacecraft propulsion system as much 1 as possible since maintenance or replacement of that system becomes particularly challenging once it has been launched into orbit from the surface of the Earth. If the size and mass of a propulsion system (including the propellant required to complete a mission) can be reduced, the amount of payload as a percentage of the total vehicle mass can be increased. The high values of specific impulse associated with electric propulsion (EP) as compared to other conventional propulsion systems results in a reduction of propellant needed for a given mission.

Inductive pulsed plasma thrusters[1-3] are spacecraft propulsion devices in which electrical energy is capacitively stored and then discharged through an inductive coil. The thruster is electrodeless, with a timevarying current in a coil interacting with a plasma covering the face of the coil to induce a plasma current.

\footnotetext{
*Senior Engineer, Electric Propulsion Department, 7902 Logan Drive, ashley.k.hallock@nasa.gov, student member AIAA.

${ }^{\dagger}$ Propulsion Research Engineer and MSFC In-space Electric Propulsion Program Lead Investigator, Propulsion Research and Technology Applications Branch,Propulsion Systems Department, kurt.a.polzin@nasa.gov, senior member AIAA

${ }^{\ddagger}$ Propulsion Research Engineer, Propulsion Research and Technology Applications Branch,Propulsion Systems Department, adam.c.kimberlin@nasa.gov.

§Undergraduate Research Assistant, University of South Florida, kperdue@mail.usf.edu, student member AIAA.
} 
Propellant is accelerated and expelled at a high exhaust velocity $(\mathcal{O}(10 \mathrm{~km} / \mathrm{s}))$ by the Lorentz body force arising from the interaction of the magnetic field and the induced plasma current.

Thrusters of this type possess many demonstrated and potential benefits that make them worthy of continued investigation. The electrodeless nature of these thrusters eliminates the lifetime and contamination issues associated with electrode erosion in conventional electric thrusters. Also, a wider variety of propellants are accessible when compatibility with metallic electrodes in no longer an issue. Inductive pulsed plasma thrusters have been successfully operated using propellants like ammonia, hydrazine, and $\mathrm{CO}_{2}$, and there is no fundamental reason why they would not operate on other in situ propellants like $\mathrm{H}_{2} \mathrm{O}$. It is well-known that pulsed accelerators can maintain constant specific impulse $\left(I_{\mathrm{sp}}\right)$ and thrust efficiency $\left(\eta_{\mathrm{t}}\right)$ over a wide range of input power levels by adjusting the pulse rate to hold the discharge energy per pulse constant. It has also been demonstrated that an inductive pulsed plasma thruster can operate in a regime where $\eta_{\mathrm{t}}$ is relatively constant over a wide range of $I_{\mathrm{sp}}$ values (3000-8000 s). Finally, thrusters in this class have operated in single-pulse mode at high energy per pulse, and by increasing the pulse rate they offer the potential to process very high levels of power using a single thruster.

During early investigations [4], several smaller-scale inductive pulsed plasma thrusters were constructed for proof-of-concept experiments in which the effect of the driving circuit properties on thruster efficiency were investigated. The difficulties of propellant utilization efficiency were revealed by experiments where thrusters with a planar inductive coil placed in backfilled environments outperformed those employing pulsed propellant injection. In more recent low-energy backfilled experiments employing a separate upstream preionization source, a current sheet was only produced by a flat inductive coil when a sufficiently strong magnetic field was applied parallel to the coil to divert the natural diffusive path of charged particles exiting the upstream ionization source [5].

One proposed approach to the challenge of efficiently achieving a uniform propellant density over the face of the inductive coil is to alter the coil geometry such that it more closely aligns with the natural path followed by the injected propellant. In the rest of this paper we first describe an experiment to investigate the operating characteristics of inductive pulsed plasma thrusters (employing preionization) possessing conical theta pinch coils of different geometries (specifically different cone angles and major radii). After this description, experimental results are presented and analyzed, followed by conclusions.

\section{Experiment}

In this section, details about the facility, test hardware, and thruster systems used to support the collection of data on the operating characteristics of inductive pulsed plasma thrusters are presented.

\section{A. Vacuum Facility}

The vacuum facility used in these experiments is a $7.6-\mathrm{m}$ (25-ft.) long stainless steel cylindrical vacuum chamber with a $2.7-\mathrm{m}$ (9-ft.) diameter. A base pressure of $7.6 \times 10^{-5} \mathrm{~Pa}\left(5.7 \times 10^{-7}\right.$ torr $)$ is maintained by two $2400 \mathrm{l} / \mathrm{s}$ turbopumps and two $9500 \mathrm{l} / \mathrm{s}$ GHe cryopumps.

\section{B. Thrust Stand}

The hanging pendulum-type Variable Amplitude Hanging Pendulum with Extended Range (VAHPER) thrust stand [6] directly measures thrust by monitoring the displacement of a thruster from an equilibrium point as a function of time. The stand, capable of supporting thrusters with masses up to $125 \mathrm{~kg}$ that produce between $100 \mu \mathrm{N}$ and $1 \mathrm{~N}$ of steady-state thrust. More information about the thrust stand in its steady-state configuration can be found in Ref. [6].

Displacement of the thrust stand arm is measured with the use of a linear gap displacement transducer (LGDT). The stand was recently modified through the addition of a pulsed calibration mechanism to accommodate pulsed thrusters. The thrust stand was calibrated for pulsed thrusters by sending a pulse of current through a solenoid mounted to a fixed point not on the moving thrust stand arm. The electromagnetic field from the solenoid acts against a permanent rare-earth magnet on the thrust stand arm, repelling it. This force is trasmitted to the arm through a piezoelectric force transducer, providing a direct measurement of the force time history. The calibration is achieved by knowing the time-history of thrust stand arm displacement, measured with the LGDT, and the force, which can be integrated to yield the impulse bit $I_{b i t}$ (impulse per 


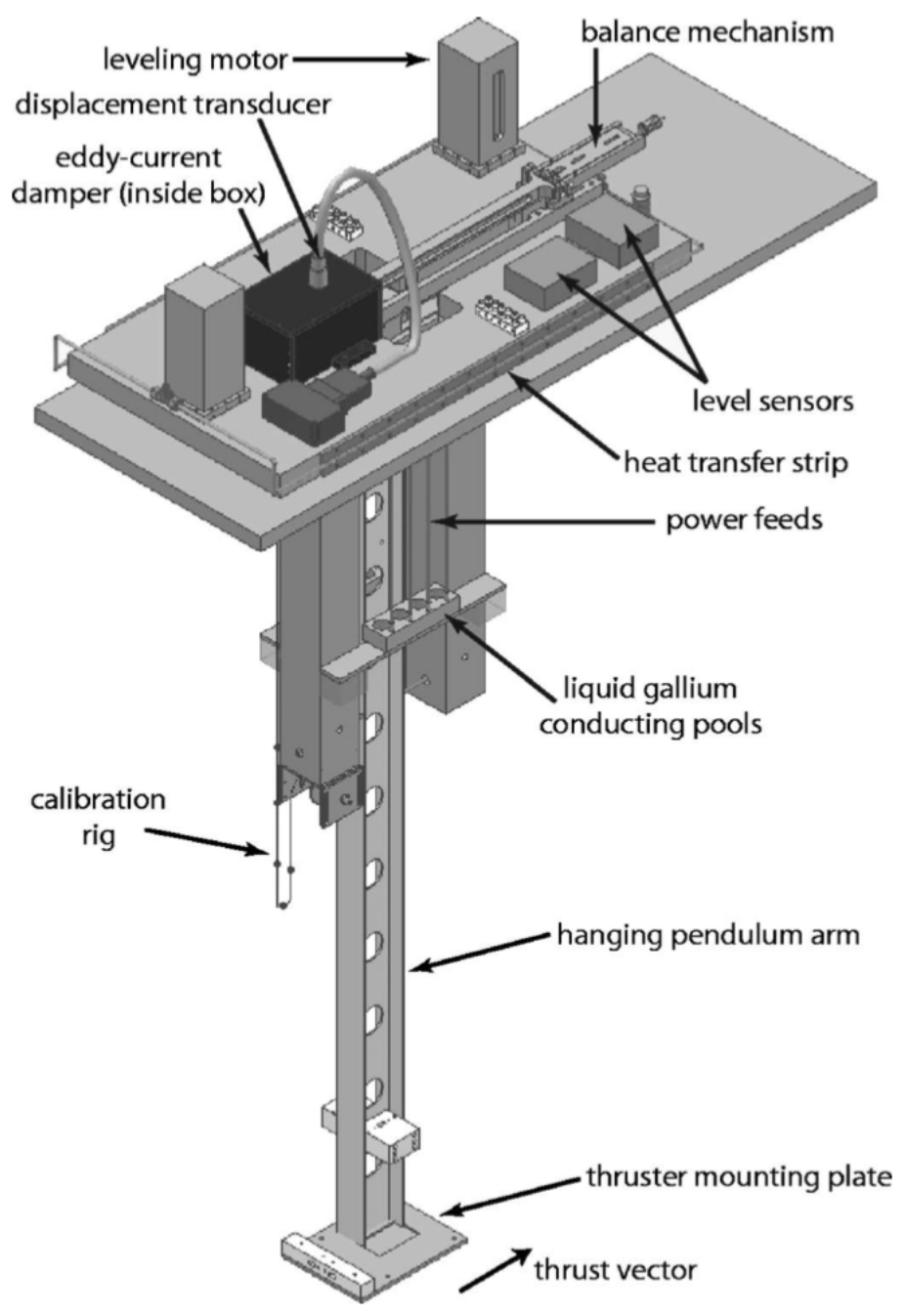

Figure 1. VAHPER thrust stand, image from Ref. [6].

pulse). More information on this setup, shown in Fig. 2, and the pulsed calibration technique can be found in Ref. [7].

\section{Thruster Description}

\section{Inductive Coil}

Two conical inductive coils were constructed for performance testing with a coil length $l_{\text {coil }}=10 \mathrm{~cm}(4 \mathrm{in})$ and minor radius $r_{\text {coil }}=4 \mathrm{~cm}(1.6 \mathrm{in})$. Of the two coils, one half cone angle $\theta=20^{\circ}$, while the other $\theta=$ $38^{\circ}$. Coil geometry is labeled in Fig. 3. The inductance of both coils is $240 \pm 20 \mathrm{nH}$ as measured at the coil leads using an Agilent 4285A precision LCR meter. The coil with $\theta=38^{\circ}$ is shown in Fig. 3 prior to being encased in RTV to insulate the coil surface from the ionized propellant. This insulating layer was covered with aerosol boron nitride to prevent ablation of the RTV surface.

The coils were designed to be like the Pulsed Inductive Thruster ${ }^{2,3}$ (PIT), possessing conducting paths in two layers that, when superimposed, create a purely azimuthal current at the coil face. Kapton-insulated 22 gauge wire carries the current, with sixteen single-turn (half-turn per layer) windings comprising the coil and connected in parallel to a common, circular current feed of one-inch wide, twelve gauge flat copper speaker wire. The circular current feed has an axial cut at one azimuthal location to interrupt any induced azimuthal eddy currents in the feed. The two conducting layers are separated by two layers of $0.25 \mathrm{~mm}$ (0.01 in) thick mylar. 


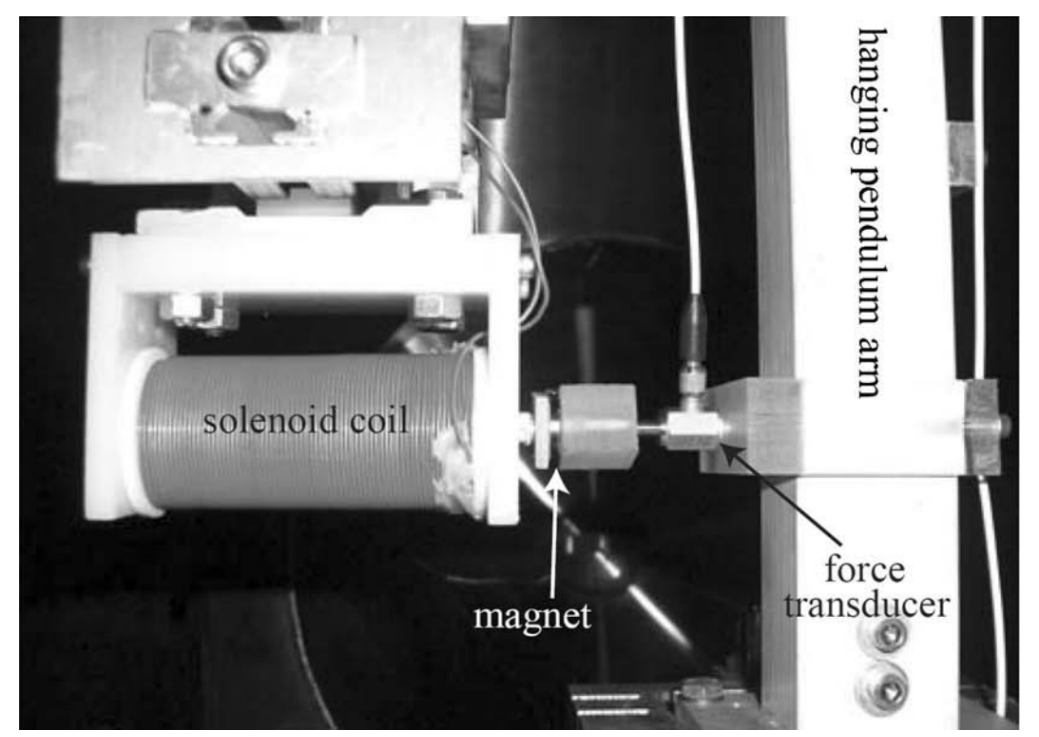

Figure 2. Photograph of the thrust stand calibration setup [7].
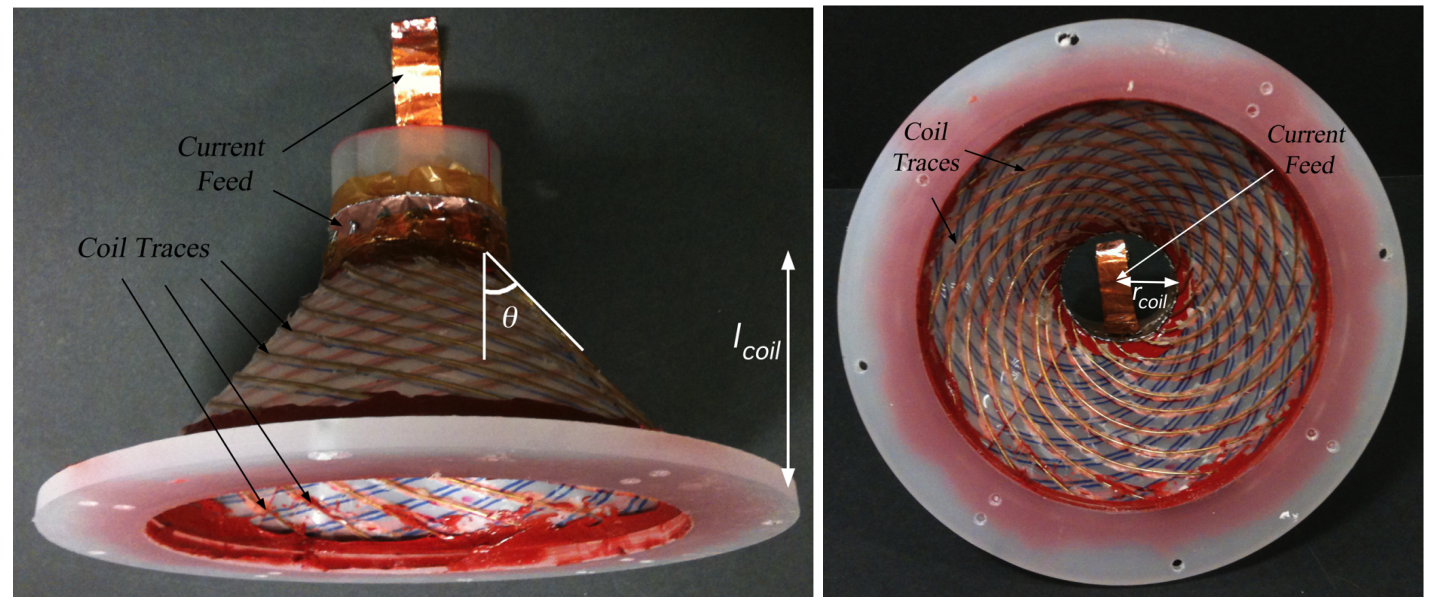

Figure 3. Photographcs of the inductive coil taken Left: from the top and right: along the thrust axis.

\section{Preionization and Propellant Injection}

The capacitors in some inductive accelerators, like the PIT [1-3], must be charged to high voltages so that the discharge current through the inductive coil can first ionize the propellant. One way to alleviate this high voltage requirement is to partially ionize the propellant in front of the inductive coil to permit inductive interaction and energy transfer to the propellant [5], allowing for a lower initial voltage in the energy storage system.

The use of preionization in inductive plasma propulsion is ubiquitous throughout the literature with a wide range of applications including plasma fusion and spacecraft propulsion. For example, preionization has been successfully employed by striking a glow discharge between two electrodes [8-10], sending a separate lower-energy pulse through an inductive coil [11-13], and creating a radio frequency plasma $[1,14]$.

Preionization was employed in the thrusters studied here to lower the voltage requirements of the driving circuit. This simplified the construction of the experimental setup with respect to capacitor and switch voltages, and reduced the voltage level the electrical insulation needed to withstand. The driving circuit for the preionizer was fed by a low-current AC power supply powered by a $12 \mathrm{~V}$ battery. The output of the AC supply was fed through a rectifier to produce a DC voltage that was then applied to the electrodes, producing a glow discharge oriented in the axial direction (see Fig. 5). The resulting voltage after breakdown 

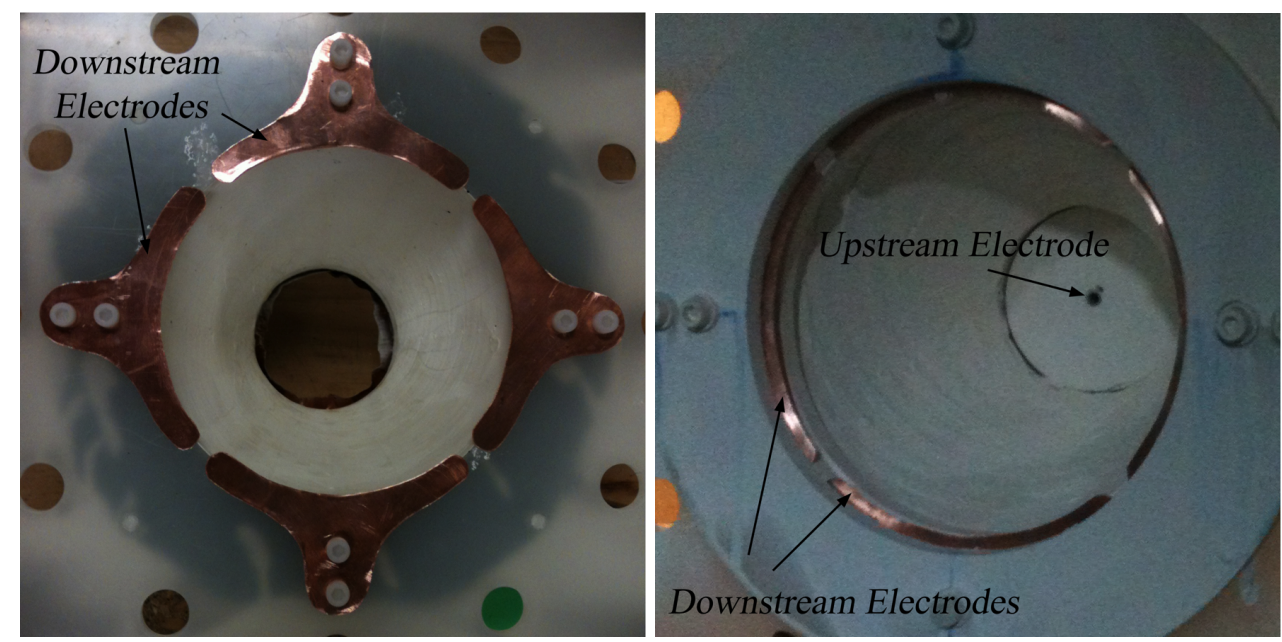

Figure 4. Photographs of Left: the downstream electrodes with a cover removed and Right: both electrodes with the cover attached.

was achieved was $300 \mathrm{~V}$. An unfiltered 16 second exposure of the preionizer operating on $150 \mathrm{mg} / \mathrm{s}$ of argon is shown in Fig. 5.

A glow discharge was initiated prior to the main current pulse through the inductive coil. The downstream electrodes are composed of copper and were segmented so as to avoid presenting a continuous azimuthal conductive path that could support eddy currents, which would draw energy from the pulsed discharge. The upstream electrode was a six inch long section of $0.635 \mathrm{~mm}(0.25 \mathrm{in})$ stainless steel tubing through which propellant was injected.

Propellant flowed to the upstream electrode through a polyethylene tube that electrically isolates the electrode. Mass flow rate was measured with an MKS metal-sealed type 1479A flow controller with maximum flow rate of 10,000 sccm. Research grade argon propellant was used for all data presented here.

\section{High Power Switch and Capacitor Bank}

A simple mechanical switch, shown in Fig. 6, is used to discharge the capacitor bank. The switch was designed to minimize inductance, adding less than $50 \mathrm{nH}$ to the driving circuit. The switch was located external to the vacuum vessel and was activated manually. Measurement of the fast-rising current pulse that resulted from closing the switch was used as a trigger for all data acquisition.

The capacitor bank consisted of four $10 \mu \mathrm{F}$ capacitors rated to $7.5 \mathrm{kV}$. The capacitors were connected in parallel, decreasing the inductance they presented to the driving circuit and increasing the total capacitance to $40 \mu \mathrm{F}$. Stripline constructed from 1 inch wide 12 gauge flat speaker wire was used to connect the capacitor to the switch and thruster.

\section{E. Experimental Setup}

The thruster was mounted onto the thrust stand as shown in Fig. 7. The capacitor bank and switch were located outside of the chamber to reduce the challenge of holding-off high voltage and allow access to the mechanical switch. Parasitic inductance was minimized where possible with the use of stripline to connect all components of the system. Results from performance testing using this un-optimized setup appear in the next section.

\section{Measurements and Analysis of Thruster Operating Characteristics}

Results of the experiment described in the previous section are presented and discussed, beginning with measurements of the capacitor bank voltage and current pulse as a function of time, followed by thrust stand measurements and time-integrated photographs of the discharge. 


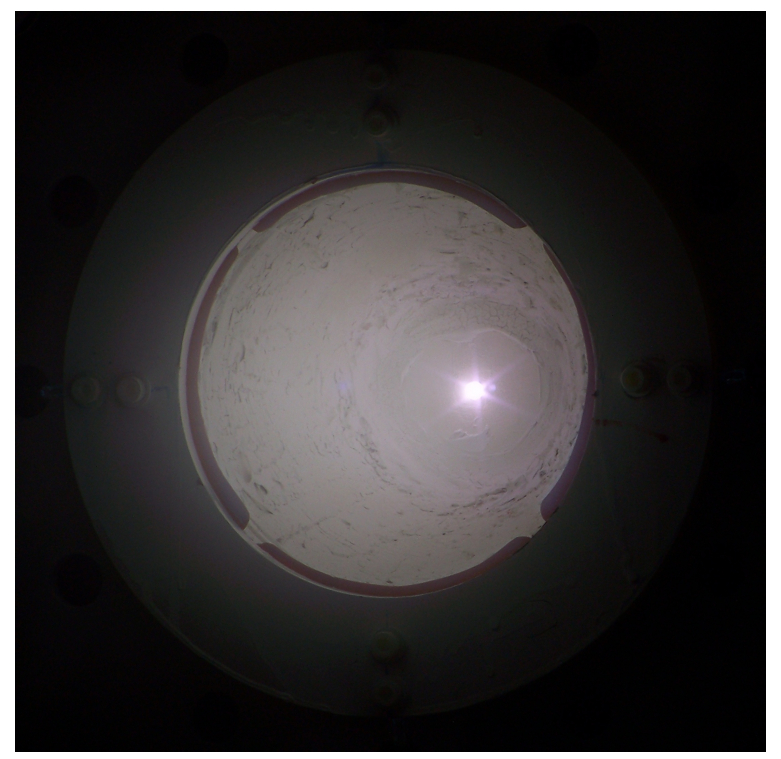

Figure 5. Unfiltered 16 second exposure of the preionized proellant at $\dot{m}=150 \mathrm{mg} / \mathrm{s}$.

\section{A. Capacitor Bank Voltage and Driving Current}

Typical capacitor bank voltage $V_{0}$ and circuit current waveforms measured during a typical discharge event appear in Fig. 8.

The voltage at the thruster terminals during a pulse was measured using a differential voltage probe at capacitor bank voltages of 100, 200, and $300 \mathrm{~V}$ and is shown in Fig. 9. The peak-to-peak voltage limits on the differential probe limited the voltage range over which this test could be performed. The fraction of bank voltage that appeared across the thruster terminals during the discharge was $\sim 31 \%$ in all three cases. If this linearity is assumed to extend up to $5 \mathrm{kV}$, then the maximum voltage that could appear during a pulse across the thruster in the present configuration is $1.55 \mathrm{kV}$.

\section{B. Impulse Calculations}

The displacement time-history of the thrust arm produced by operation of two different thrusters, one with $\theta=20^{\circ}$ (designated as thruster 20L) and the other with $\theta=38^{\circ}$ (designated thruster 38), was measured for various values of capacitor voltage $V_{0}$ and mass flow rate $\dot{m}$. The thrust arm dynamics are well-described as a spring-mass-damper system. The total change in thrust arm velocity was calculated by fitting an analytical damped-sinusoidal function to the displacement measurements and evaluating the derivative at the time of thruster operation, which was assumed to be impulsive on the timescale of thrust arm movement. The total impulse was calculated from measurements of thrust stand arm displacement using an independent calibration factor determined by applying known impulse bits to the thrust stand.

\section{Effective Mass Calculation: Thrust Stand Calibration}

Deflection of the thrust stand arm is measured with an linear gap displacement transducer (LGDT). An impulse is imparted to the thrust stand arm by a current pulse through solenoid coil mounted to a static portion of the thrust stand. The electromagnetic field from the solenoid acts against a permanent magnet mounted to a force transducer. This force transducer is attached directly to the movable thrust stand arm and permits measurement of the force applied during a calibration pulse. The force is recorded and integrated to calculate the total $I_{b i t}$ imparted to the thrust stand arm. A representative force transducer measurement and the commensurate impulse appear in Fig. 10.

The displacement of the thrust stand arm before and after the time of impact is fitted using an exponentiallydecaying sinusoidal function, yielding analytical expressions that can be differentiated to obtain the velocity of the arm. The discontinuous impulsive change in the velocity produced by the pulse can be found by evaluating the difference in the position derivatives at $t=0^{-}$and $t=0^{+}$. By assuming the stand acts 


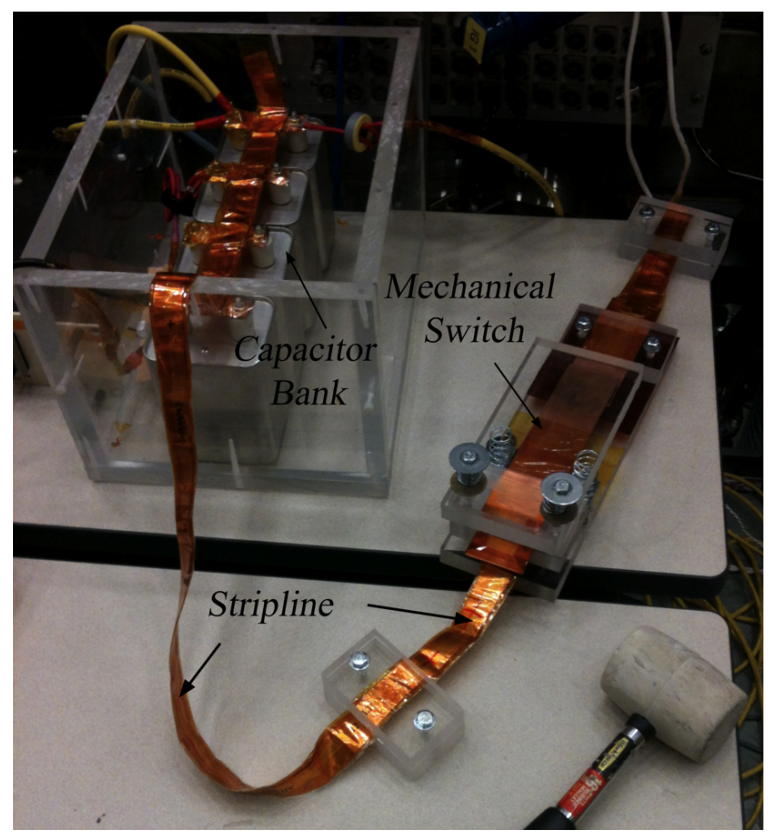

Figure 6. Photograph of the capacitor bank and mechanical switch.

as an ideal spring-mass-damper system, and that the force is impulsive (duration of force $\ll$ thrust stand arm period), it follows that the impulse and change in thrust stand arm velocity (and also momentum) are linearly related [15]. The LGDT signal and the curve fit of the motion for $t>0$ are shown in Fig. 11.

The change in velocity is calculated for various values of $I_{b i t}$ and the constant of proportionality is taken to be the calibration coefficient or effective mass of the thrust stand arm. A correction is made to the effective mass calculation to account for the difference in the moment arms from the force transducer and the centerline of the thruster to the pivot point of the thrust stand arm. The pivot point is $66 \mathrm{~cm}(26 \mathrm{in})$ above the force transducer and $97.5 \mathrm{~cm}$ (38.4 in) above the centerline of the thruster.

\section{Thrust Arm Displacement Measurements}

Thrust arm displacement measurements are shown in Fig. 13 for thruster 20L and thruster 38 while curve fitting results are shown overlaying these measurements for $t>0$ in Fig.14.

While curve fitting results for displacement measurements of thruster 20L represent the data well, displacement measurements for the thruster with a $38^{\circ}$ half cone angle (designated as thruster 38) appear to be distorted by signal noise, resulting in a poor curve fit. Both signals are weak, however measurements for thruster 20L can be fitted to a damped sinusoidal function and analyzed to obtain a value of $I_{b i t}$. The displacement data of thruster 38 are too low in amplitude to be reliably analyzed in this way. These measurements reveal that the displacement of the thrust stand due to the impulse imparted by thruster 20L is larger than the displacement from operation of thruster 38.

\section{Impulse Calculation}

All data that follow were obtained using argon propellant. Results of calculations for $I_{b i t}$ of thruster $20 \mathrm{~L}$ are shown in the left side of Fig. 15 for various values of $\dot{m}$ obtained at $V_{0}=5 \mathrm{kV}$. The calculated value for the $I_{\text {bit }}$ attains a maximum value of $0.097 \mathrm{mN}$-s for $90<\dot{m}<150 \mathrm{mg} / \mathrm{s}$.

The base pressure in the vacuum vessel is shown in the right side of Fig. 15 as a function of $\dot{m}$. For values of $\dot{m}$ greater than $150 \mathrm{mg} / \mathrm{s}$, the base pressure rose above 1 mTorr, which implies that the back pressure in the tank is great enough to exert a detrimental drag force on an exhausting current sheet. the higher pressure also increases the voltage insulation requirements along the stripline feeding power to the thruster from outside the vessel. 


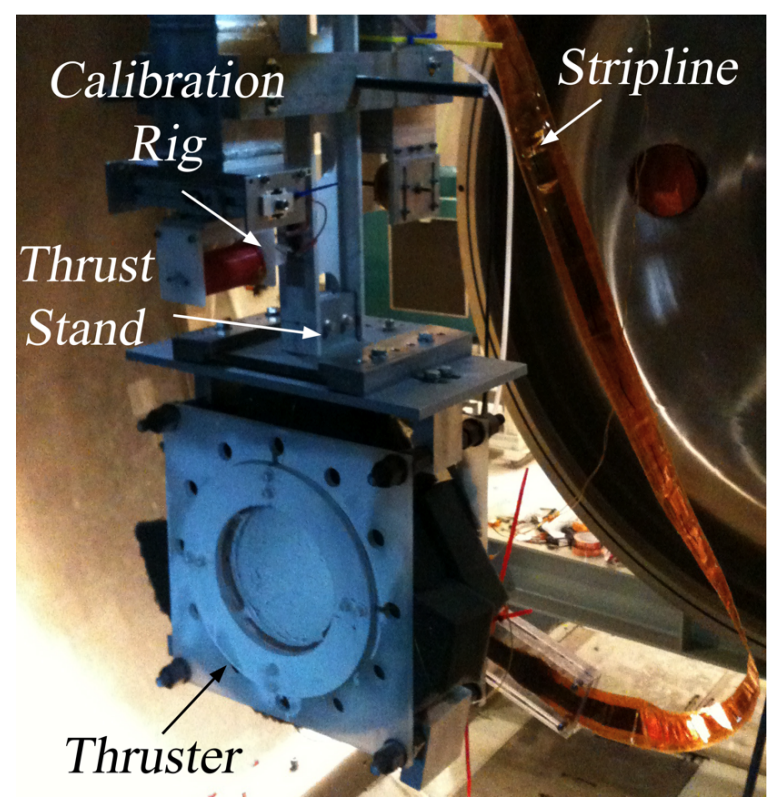

Figure 7. Thruster mounted on the thrust stand.

\section{Photographic Evidence}

All photographs of thruster operation were unfiltered and obtained using a Kodak Z812 IS SLR digital camera with an ISO setting of 64, a focal ratio of 8 and an exposure time of 1 second. All image-altering functions of the camera, including white balance and automatic focusing, were disabled. The camera was pointed at the thruster, offset approximately $10^{\circ}$ from the thruster centerline located $6 \mathrm{~m}(20 \mathrm{ft})$ downstream from the thruster exit plane.

Images of the preionization were obtained and digitally subtracted from images of the plasma during a main current pulse through the coil to remove any ambiguity regarding the source of the light with respect to these two separate processes. Results from previous studies [16-18] have shown that light intensity qualitatively agrees well with regions of higher current density. Assuming this to be the case here aw well, we draw conclusions about trends in current sheet location based on the brightness of light in photographs. It cannot be overstated that any conclusions reached using these time-integrated, unfiltered photographic data are restricted to qualitative trends only (in recognition of this uncertainty).

Photographs of thruster 20L operating on $120 \mathrm{mg} / \mathrm{s}$ are shown in Fig. 16 for three different values of $V_{0}$. As $V_{0}$ is decreased, the brightness of the discharge also decreases, suggesting (not surprisingly) that as $V_{C}$ decreases a smaller current density is driven in the preionized propellant. Also with decreasing $V_{0}$, the location of the brightest light in the photograph moves downstream (towards the exit of the cone).

A previous study [19] showed that the current sheet formation process depends on a ratio of the voltage appearing at the thruster (which is directly proportional to $V_{0}$ ) to the propellant pressure, indicating the existence of a Townsend-like breakdown process. For this type of breakdown, the electrons attain energies well above those necessary for ionization at lower values of $\dot{m}$ (lower values of neutral density), but undergo fewer ionizing collisions with the background neutrals. As the value for $\dot{m}$ is raised, the number of collisions between electrons and neutral particles increases, however the energy gained by the electrons from the electric field (created by the current pulse) between collisions decreases due to a shortened electron-neutral mean free path. At values of $\dot{m}$ above the optimum, the ionization rate becomes limited by the amount of energy the electrons are able to acquire between collisions as opposed to values below the optimum where the ionization rate is limited by the availability of target neutral particles. These competing effects lead to the existence of an optimum ratio of electric field (proportional to $V_{0}$ ) to pressure (proportional to $\dot{m}$ ).

Propellant injection occurs at a single point along the centerline of the thruster at the upstream end of the coil and diffuses axially downstream into the vacuum vessel, leading to a lower pressure at the downstream end of the coil as compared to the upstream end. If this trend in light intensity is representative of a similar trend in current density, a possible explanation is that as $V_{0}$ is lowered, the optimum pressure for current 

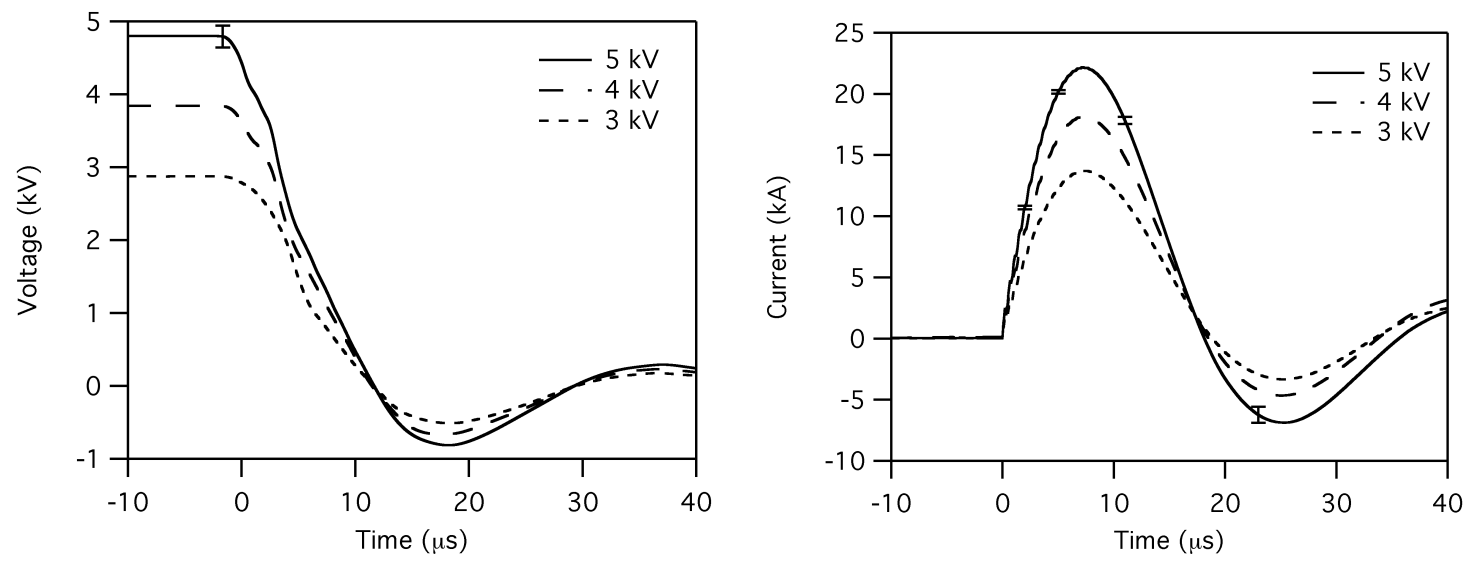

Figure 8. Typical capacitor bank discharge voltage and circuit current as a function of time with representative error bars shown.

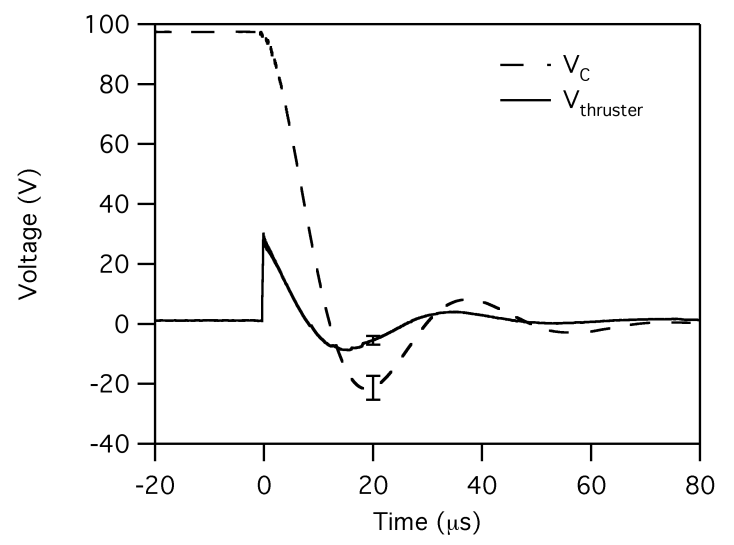

Figure 9. Voltage measurements at the capacitor bank and at the thruster terminals during discharge for $V_{0}$ $=100 \mathrm{~V}$ with representative error bars shown.

sheet formation is also lowered, leading current sheet formation to be preferentially shifted towards the downstream end of the coil.

Photographs of thruster 20L operating on argon with decreasing $\dot{m}$ are presented in Fig. 17 for $V_{0}=5 \mathrm{kV}$. As $\dot{m}$ is decreased, the brightness of the discharge also decreases, suggesting as in the case for decreasing $V_{0}$ that a smaller current density is driven in the preionized propellant. Also as $\dot{m}$ decreases, the location of the brightest light moves either radially inwards or upstream towards the point of propellant injection, both directions appearing the same in these time-integrated photographs. If this trend in light intensity is representative of a similar trend in current density, a possible reason for this trend is that as $\dot{m}$ is lowered, the optimum pressure for current sheet formation moves upstream and towards the centerline of the thruster. The decrease in overall light intensity could indicate that a smaller fraction of the total volume of propellant lying within the region of significant electromagnetic interaction with the inductive coil has a pressure close to the optimum value, with a higher fraction of the propellant volume at a pressure significantly lower than the optimum value.

Photographs of thruster 38 operating with $V_{0}=5 \mathrm{kV}$ for decreasing values of $\dot{m}$ are shown in Fig. 18 . The brightness of the discharge decreases and the brightest sections of the discharge move either towards the centerline of the thruster or the upstream end of the coil with decreasing $\dot{m}$, just as they did for thruster 20L. A similar conclusion could be drawn (as in the case of thruster 20L) that if light intensity represents current density at that location, current sheet formation is hindered along the coil face due to a paucity of target neutral particles for ionization at that location. The current sheet may be forming either in a restricted volume at the upstream end of the thruster or at a location radially-displaced from the coil. Both of these 

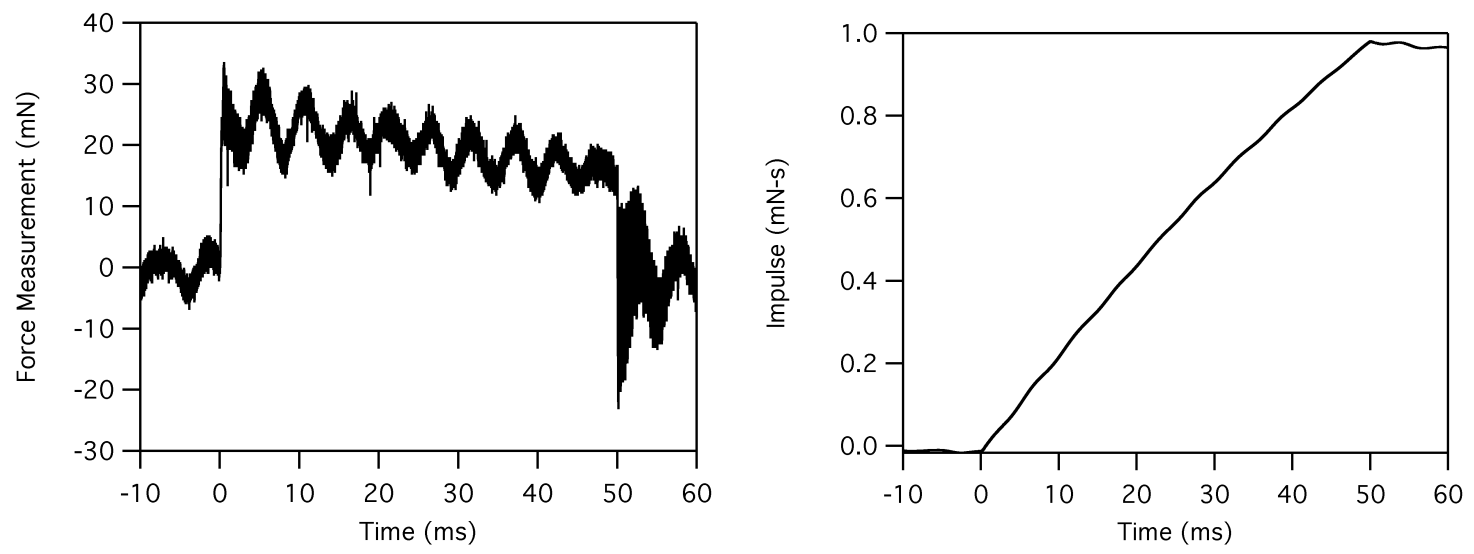

Figure 10. Signal from the force transducer and its time integral.
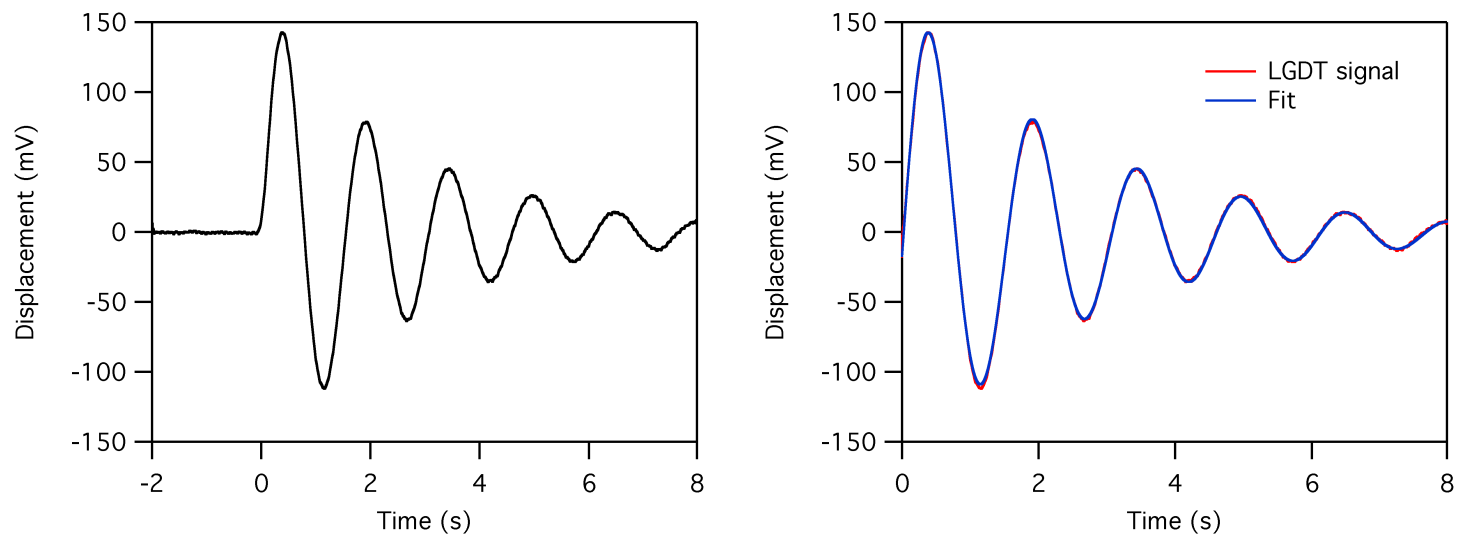

Figure 11. Left: An LGDT signal resulting from an applied impulse and Right: a comparison of the signal to a fitted damped sinusoidal waveform for $t>0$.

situations would result in decreased energy coupling from the coil to the propellant.

Two rows of photographs of thruster $20 \mathrm{~L}$ and 38 operating at the same values of $V_{0}$ and $\dot{m}$ for each row are shown in Fig. 19. The photographs were obtained at the same zoom level and camera orientation with respect to each thruster. The discrepancy in the apparent size of the bright region is due to the larger major radius of thruster 38 , which has the same minor radius and coil length as thruster $20 \mathrm{~L}$ but a larger cone angle. The discharge in thruster 20L appears brighter than the one in thruster 38 for both values of $\dot{m}$. The brightness of the discharge in thruster 38 for $V_{0} \geq 4 \mathrm{kV}$ and $\dot{m}=120 \mathrm{mg} / \mathrm{s}$ appears similar to that of photographs of thruster $20 \mathrm{~L}$ at $V_{0} \leq 3 \mathrm{kV}$ and $\dot{m} \leq 18 \mathrm{mg} / \mathrm{s}$.

\section{Summary and Conclusion}

In this paper, direct thrust stand measurements and time integrated photography for two separate conical theta pinch inductive pulsed plasma thrusters were presented. The results from these tests are summarized as follows.

The signal level of thrust stand displacement measurements for both thrusters was small, with the ratio of the displacement measurement to the noise in the data acquisition system only sufficiently large for reliable calculation of the impulse bit produced by thruster $20 \mathrm{~L}$. This indicates that thruster $20 \mathrm{~L}$ produced more axial thrust compared to thruster 38, however the fact that the generated impulse was small may indicate that the difference in thrust levels was due to an inefficient current sheet formation process rather than an inefficient current sheet acceleration. Measurements indicate that thruster 20L produces a maximum impulse bit at a mass flow rate of argon between 90 and $150 \mathrm{mg} / \mathrm{s}$ at a capacitor charging voltage of $5 \mathrm{kV}$, suggesting 


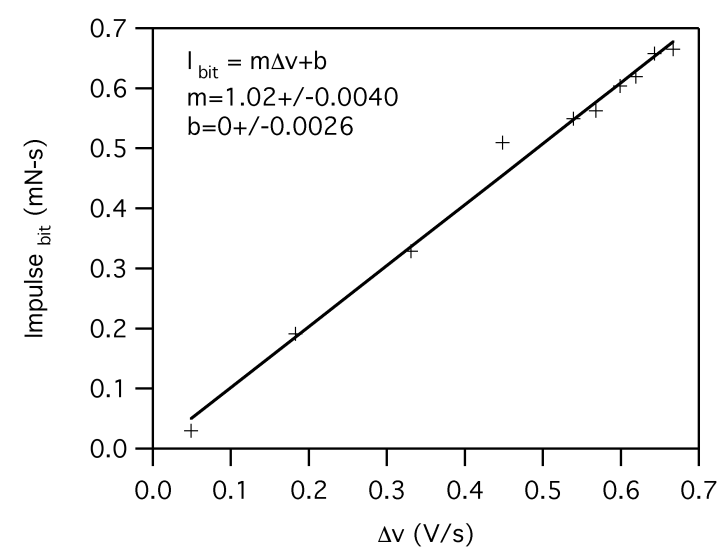

Figure 12. A plot of $I_{b i t}$ versus momentum imparted to the thrust stand by the solenoid.
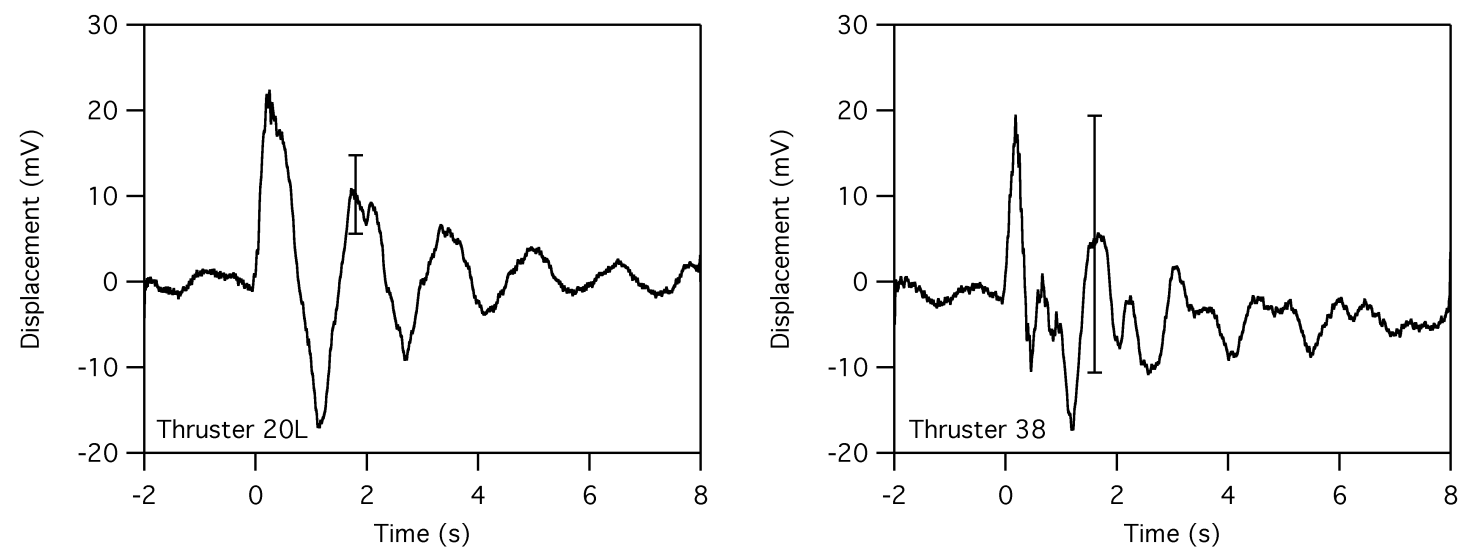

Figure 13. Thrust arm displacement measurements for left: thruster 20L and right: thruster 38 for $V_{0} 5 \mathrm{kV}$ and $\dot{m}=120 \mathrm{mg} / \mathrm{s}$ with typical error bars shown.

a dependence of current sheet formation on a Townsend-like breakdown process as described in a previous study [19].

Thruster 20L produced a brighter image than thruster 38 for the same operating conditions. Brightness of the photographs also increased with increasing mass flow rate for both thrusters and increasing capacitor charging voltage in thruster 20L. As the mass flow rate was decreased, the location of highest light intensity moved either radially inwards or upstream towards the point of propellant injection for both thrusters. As capacitor charging voltage decreased, the location of highest light intensity moved downstream for thruster 20L.

The simple propellant injection scheme employed in the experiment likely led to a gradient in propellant pressure in the volume bounded by the inductive coil. A previous study showed that values of current sheet brightness and current density produced by an inductive coil operating in a backfilled environment achieve a maximum with respect to a ratio of the voltage applied across the inductive coil and the ambient pressure [19]. If light intensity can be assumed to be a good representation of current sheet location, then a possible explanation for the trend in light intensity is that as the mass flow rate is reduced, the location of optimum propellant pressure for current sheet formation (the pressure that corresponds to the brightest and densest current sheet) moves upstream towards areas of higher relative propellant pressure. As the capacitor voltage is decreased, the propellant pressure also decreases to maintain the same optimum ratio of capacitor voltage to pressure for current sheet formation, shifting current sheet formation downstream towards areas of lower propellant pressure. The brightest areas of the brightest images of both thrusters do not appear at the downstream end of the thruster.

More tenuous current sheet formation in thruster 38 (as compared to that in thruster 20L) could be due 

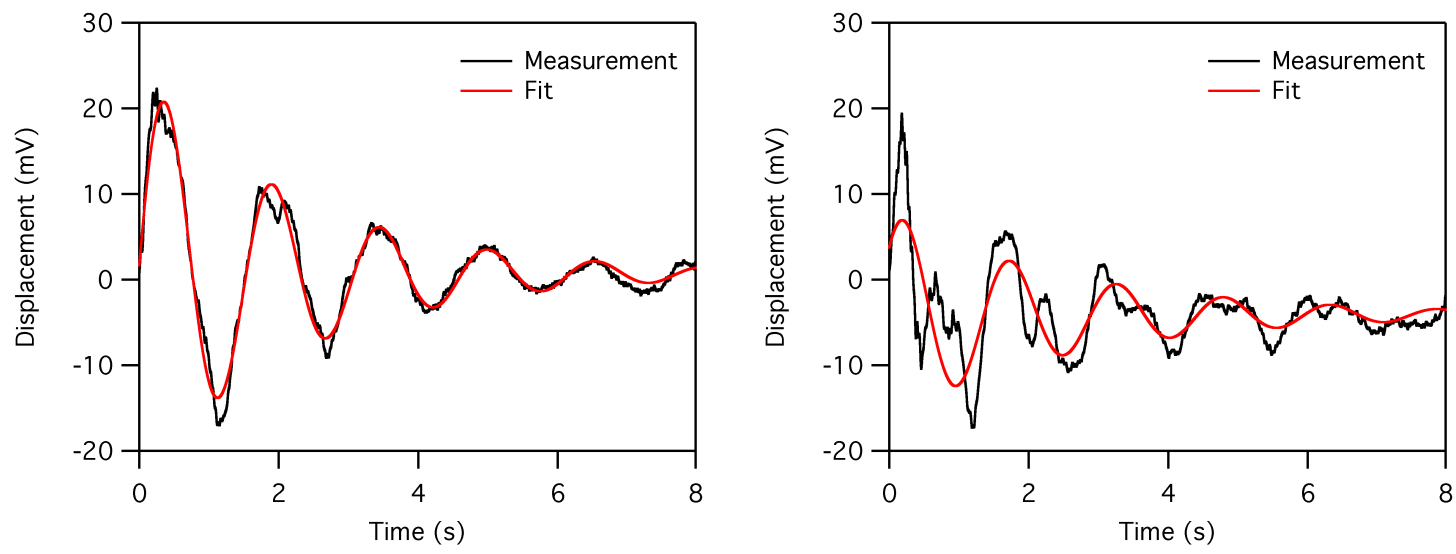

Figure 14. Curve fitting results thrust arm displacement measurements for left: thruster 20L and right: thruster 38 for for $t>0, V_{0} 5 \mathrm{kV}$, and $\dot{m}=120 \mathrm{mg} / \mathrm{s}$.
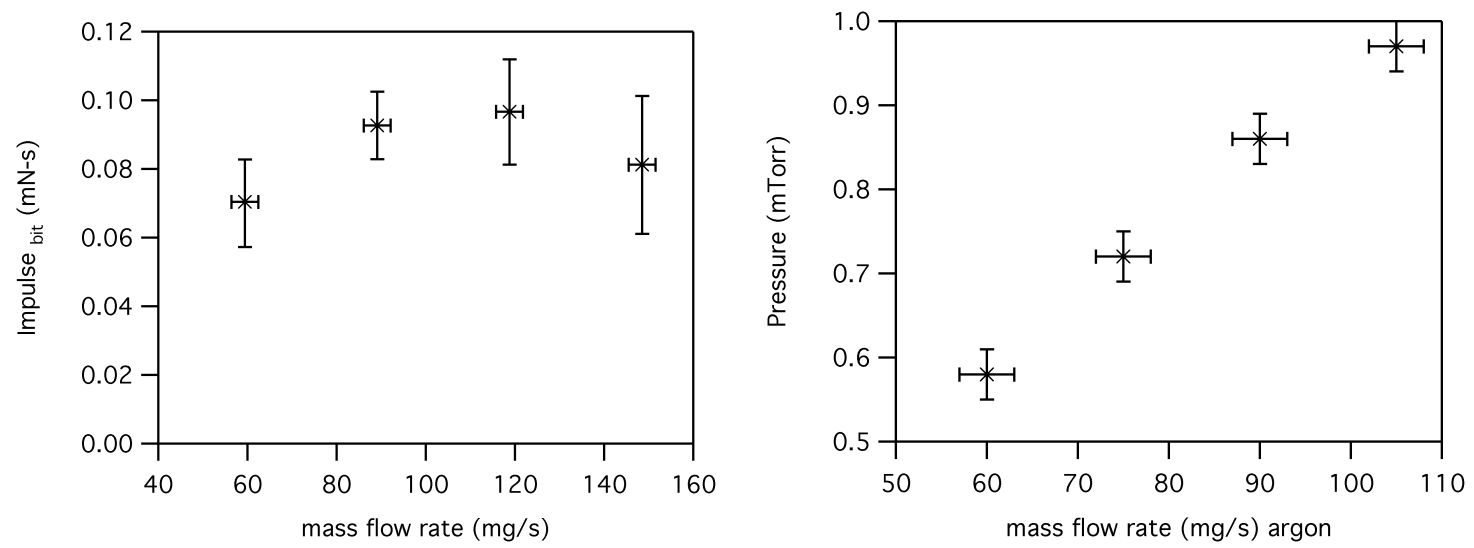

Figure 15. Left: $I_{b i t}$ for thruster 20L as a function of $\dot{m}$ with $V_{0}=5 \mathrm{kV}$ and Right: base pressure in the vacuum vessel as a function of $\dot{m}$.

to accelerated diffusion of propellant away from the inductive coil caused by a wider cone angle, which would leave behind a shortage of neutral particles for ionization reactions. Also, a radial gradient in propellant density in the inductive coil could radially displace current sheet formation away from the coil face to a location where more neutral particles are available for ionization.

While the thruster with a more cylindrical coil geometry imparted the greater impulse bit to the thrust stand, the thrust measured here is significantly inferior to competing thruster designs, with displacement measurements rising barely above the noise of the data acquisition system. This decreased thrust in both thrusters studied here relative to other thruster designs is certainly attributable in part to a large inductive voltage drop in the transmission line, among other un-optimized aspects of the experimental setup as a whole. It may also be caused by premature current sheet decoupling due to radial current sheet motion or an initially radially-displaced current sheet formation point in both thrusters (one more exaggerated than the other). The hypothesized benefits of conical theta pinch propellant utilization appear through modeling [20] to be counteracted by degradation in electromagnetic acceleration, suggesting that an optimal coil angle may exist. This optimal angle may increase as more sophisticated propellant injection systems are developed that are capable of maintaining more ideal density profiles in thrusters with inductive coils of various geometries.

\section{Acknowledgments}

The authors appreciate the help and support of Dr. Adam Martin, Mr. Richard Eskridge, Dr. Noah Rhys, Mr. J. Boise Pearson, and Mr. Jim Martin. This work was supported in part by NASA's Advanced 

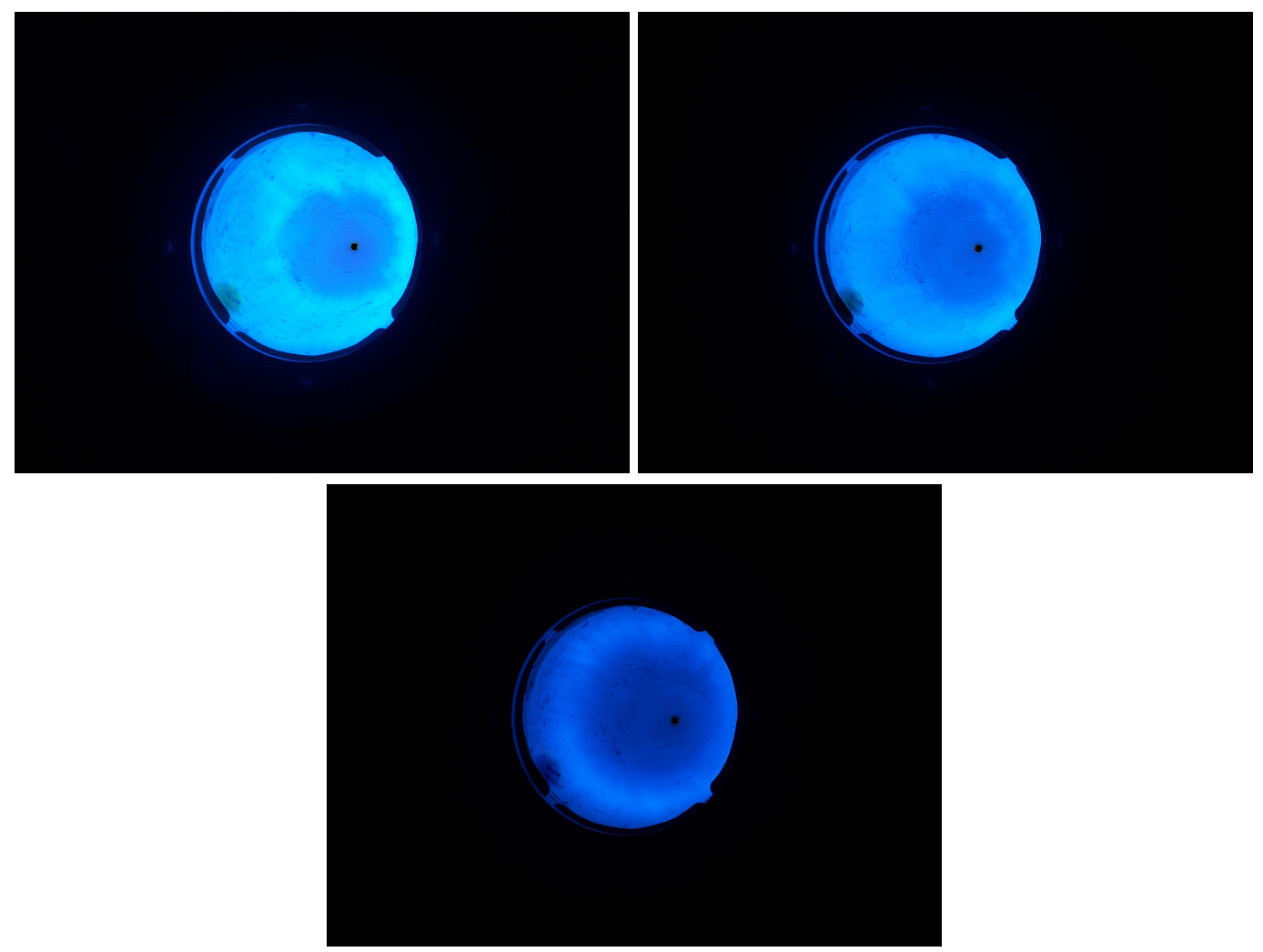

Figure 16. Time-integrated photographs of thruster $20 \mathrm{~L}$ operating on $120 \mathrm{mg} / \mathrm{s}$ with Top Left: $V_{0}=5 \mathrm{kV}$, Top Right: $V_{0}=4 \mathrm{kV}$, and Bottom: $V_{0}=3 \mathrm{kV}$.

In-Space Propulsion program managed by Dr. Michael LaPointe and the Office of the Chief Technologist In-Space Propulsion Program managed by Mr. Timothy Smith. 

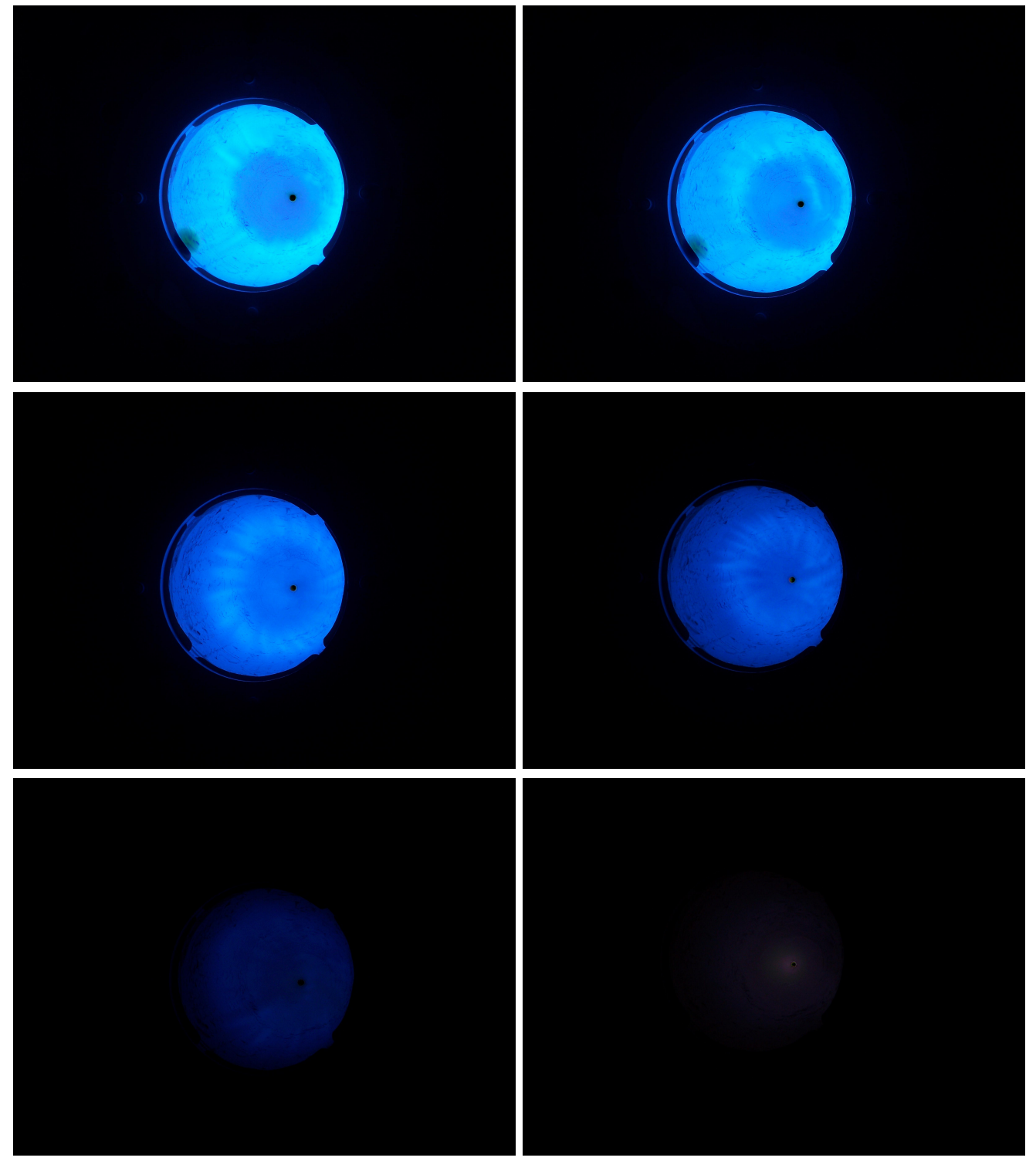

Figure 17. Photographs of $20 \mathrm{~L}$ with (left to right, top to bottom) $\dot{m}=150,90,30,18,15$, and $12 \mathrm{mg} / \mathrm{s}, V_{0}=$ $5 \mathrm{kV}$.

\section{References}

${ }^{1}$ Polzin, K. A. Comprehensive Review of Planar Pulsed Inductive Plasma Thruster Research and Technology. Journal of Propulsion and Power, 27(3):513-531, May-June 2011.

${ }^{2}$ Dailey, C. L. and Lovberg, R. H. The PIT MkV Pulsed Inductive Thruster. Technical Report 191155, Lewis Research Center, Redondo Beach, CA, July 1993.

${ }^{3}$ Lovberg, R. H. and Dailey, C. L. A PIT primer. Technical Report 005, RLD Associates, Encino, CA, 1994.

${ }^{4}$ Dailey, C. L. and Davis, H. A. Pulsed Plasma Propulsion Technology. AFRPL-TR-73-81, TRW Systems Group, July 1973.

${ }^{5}$ Polzin, K. A. Scaling and System Considerations in Pulsed Inductive Plasma Thrusters. IEEE Transactions on Plasma Science, 36(5):2189-2198, October 2008.

${ }^{6}$ Polzin, K. A. Markusic, T. E. Stanojev, B. J. DeHoyos, A. and Spaun, B. Thrust Stand for Electric Propulsion Performance Evaluation. Review of Scientific Instruments, 77:105-108, October 2006.

${ }^{7}$ Toftul, A. Wong, A. R. Polzin, K. A. and Pearson,J.B. Non-contact Thrust Stand Calibration Method for Repetitively Pulsed Electric Thrusters. Review of Scientific Instruments, 83, February 2012. 1961.

${ }^{8}$ Josephson, V. and Hales, R. W. Parametric Study of the Conical Shock Tube. The Physics of Fluids, 4(3):373-379, 

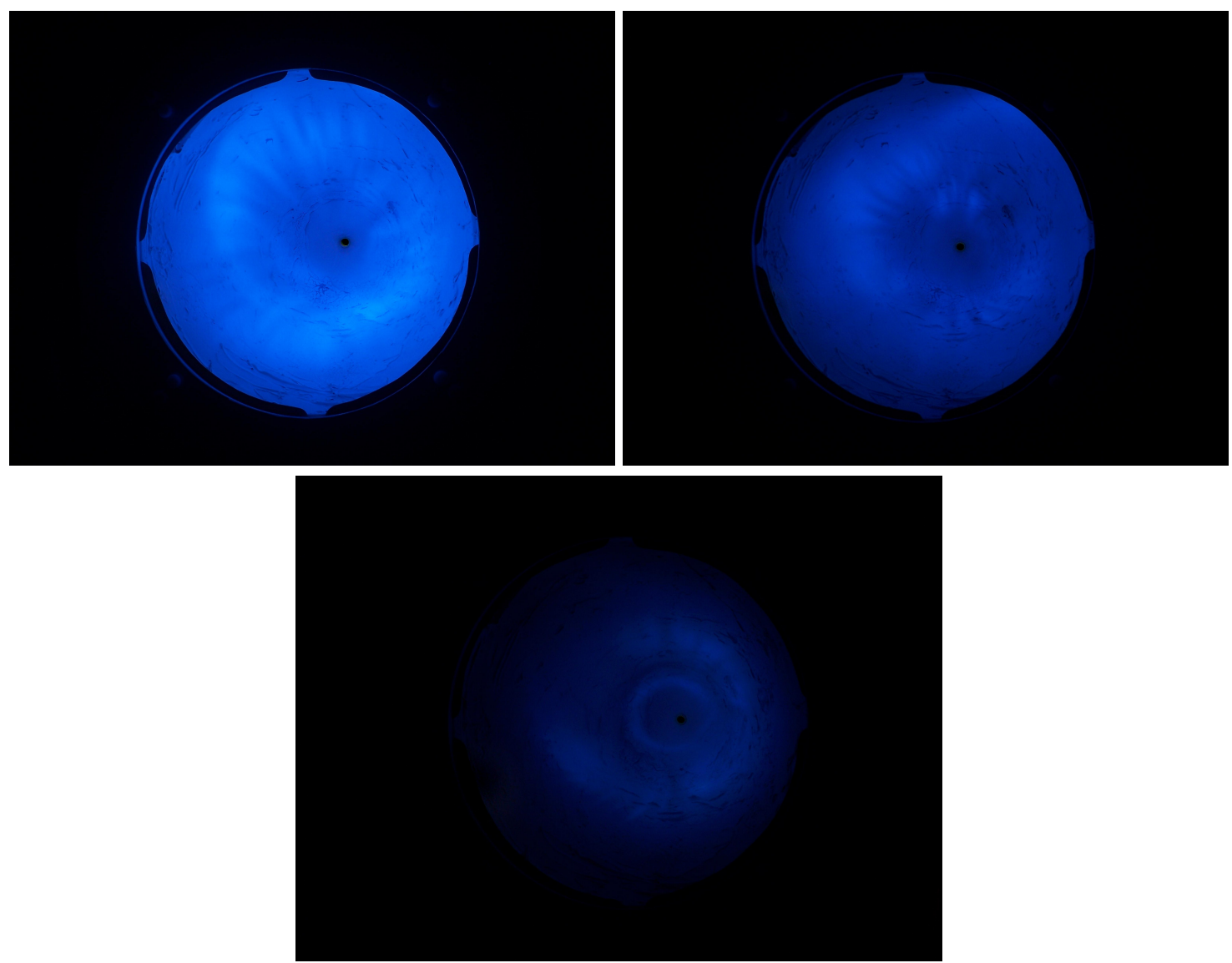

Figure 18. Time-integrated photographs of thruster 38 operating on Top Left: $120 \mathrm{mg} / \mathrm{s}$, Top Right: $90 \mathrm{mg} / \mathrm{s}$, and Bottom: $45 \mathrm{mg} / \mathrm{s}$ with $V_{0}=5 \mathrm{kV}$.

${ }^{9}$ Fimognary, P. J. Cassibry, J. T. and Ims, K. E. Effects of Pre-ionization and Bias Field on Plasmoid Formation and Acceleration. Number AIAA-2007-5262, July 2007.

${ }^{10}$ Eskridge, R. H. Fimognari, P. J. Martin, A. K. and Lee, M. H. Design and Construction of the PT-1 Prototype Plasmoid Thruster. Technical report, Propulsion Research Center, NASA Marshall Space Flight Center, 2005.

${ }^{11}$ Josephson, V. Production of High Velocity Shocks. Journal of Applied Physics, 29(1):30-32, 1958.

${ }^{12}$ Cruddace, R. C. and Hill, M. Mechanism of Plasma Acceleration in a Conical Theta-pinch Gun. Technical Report CLM-M52, Culham Laboratory, 1966.

${ }^{13}$ Niemela, C. S. and Kirtley, D. E. Initial Results on an Annular Field Reversed Configuration Plasma Translation Experiment. Technical Report AFRL-RZ-ED-TP-2008-489, Air Force Research Laboratory, November 2008.

${ }^{14}$ Kirtley, D. E. Gallimore, A. D. Haas, J. and Reilly, M. High Density Magnetized Toroid Formation and Translation with xocot: An annular field reversed configuration plasma concept. Technical Report AFRL-PR-ED-TP-2007-387, Air Force Research Laboratory, August 2007.

${ }^{15}$ Cubbin, E. A. Ziemer, J. K. Choueiri, E. Y. and Jahn, R. G. Pulsed thrust measurements using laser interferometry. Review of Scientific Instruments, 68(6):2339-2346, June 1997.

${ }^{16}$ Hoskins, W. A. Asymmetric Discharge Patterns in the MPD Thruster. Master's thesis, Princeton University, Department of Mechanical and Aerospace Engineering, 1990.

${ }^{17}$ Markusic, T. E. and Choueiri, E. Y. Photographic, Magnetic, and Interferometric Measurements of Current Sheet Canting in a Pulsed Electromagnetic Accelerator. Number AIAA 2001-3896, July 2001.

${ }^{18}$ Markusic, T. E. Choueiri, E. Y. and Berkery, J. W. Measurements of Current Sheet Canting in a Pulsed Electromagnetic Accelerator. Physics of Plasmas, 11(10), October 2004.

${ }^{19}$ Hallock, A. K. Current Sheet Formation in a Conical Theta Pinch Faraday Accelerator with Radio Frequency Assisted Discharge. Master's thesis, Princeton University, Department of Mechanical and Aerospace Engineering, November 2008.

${ }^{20}$ Hallock, A. K. Polzin, K. A. . Two-dimensional Analysis of Conical Pulsed Inductive Plasma Thruster Performance. Number JANNAF-2011-2197, September 2011. 

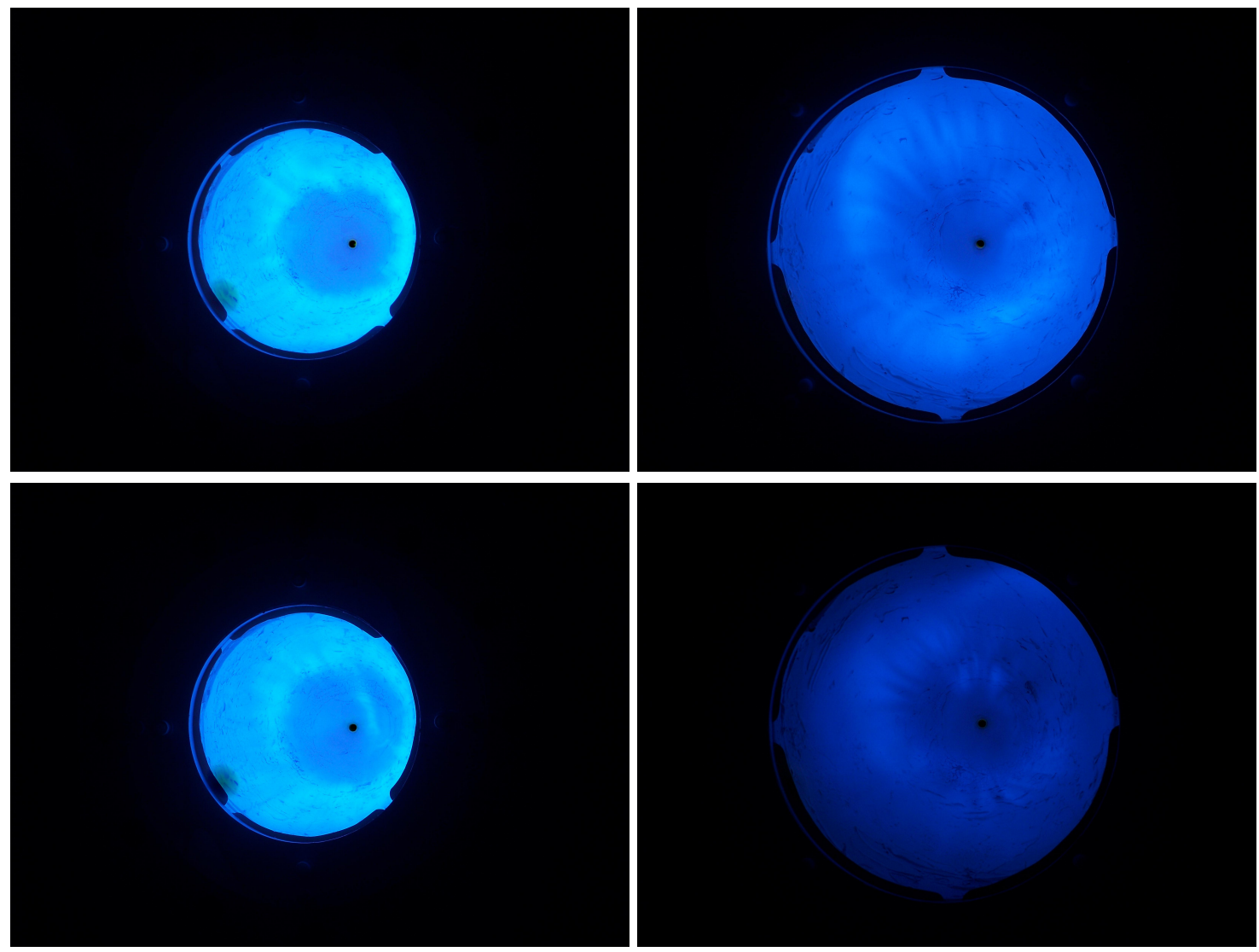

Figure 19. Time-integrated photographs of thruster 20L and 38 operating on Top: $120 \mathrm{mg} / \mathrm{s}$ and Bottom: 90 $\mathrm{mg} / \mathrm{s}$ with $V_{0}=5 \mathrm{kV}$. Photographs were obtained at the same zoom level and camera orientation with respect to each thruster. 


\section{Effect of Inductive Coil Geometry on the Operating Characteristics of an Inductive Pulsed Plasma Thruster.}

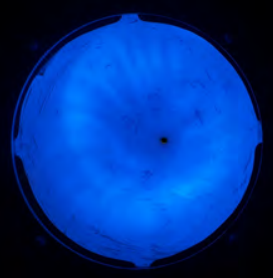

Ashley K. Hallock Kurt A: Polzin

\section{Adam C. Kimberlin.}

Kevin A. Perdue 


\section{Outline of Talk}

䝛 Inductive Pulsed Plasma Thrüsters

- Operation

- What is the optimum coil geometry?

Model

Experiment

Experimental Results

- Imipulse Measurements

- Time-integrated Photographs

Discussion of Experimental Results

Conclusions. 


\section{Inductive Pulșed Plasma. Thrusters}




\section{Inductive Pulsed Plasma Thruster Operation}

Idealized thruster operation :

Capacitors

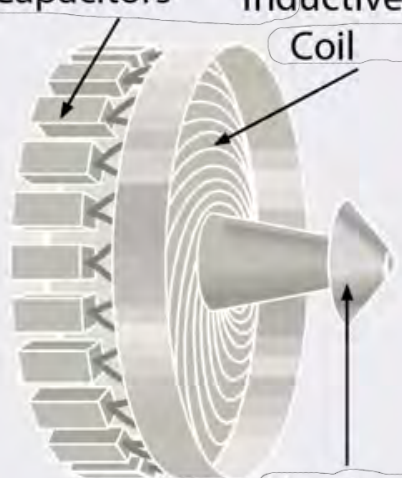

Propellant Nozzle
:

Inductive

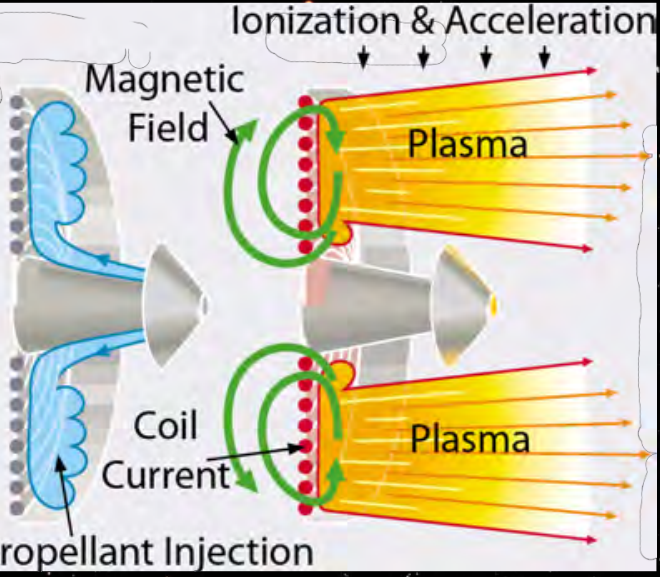




\section{Question: What is the Optimum Coil Geometry?}

\section{Capacitors Inductive}

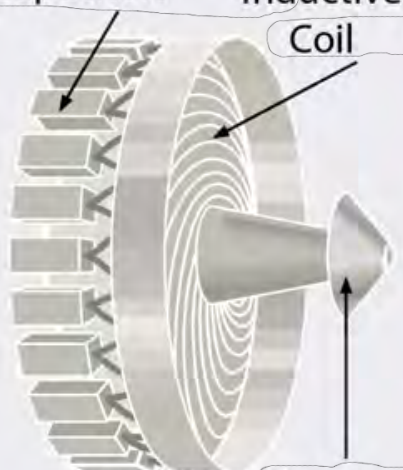

Propellant Nozzle
西

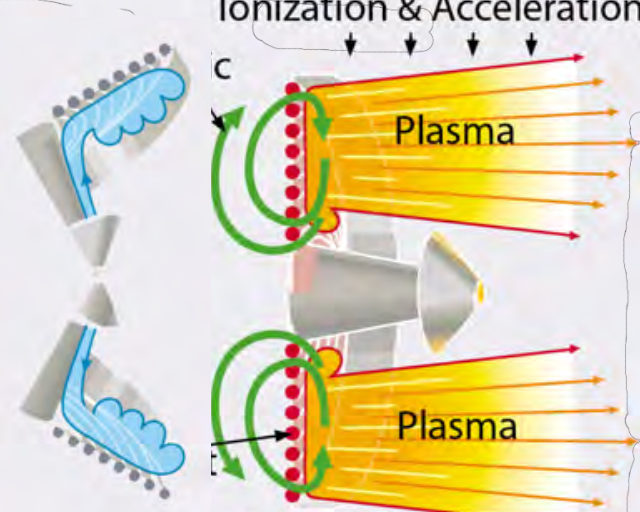

Propellant Injection 


\section{Question: What is the Optimum Coil Geometry?}

\section{Capacitors}

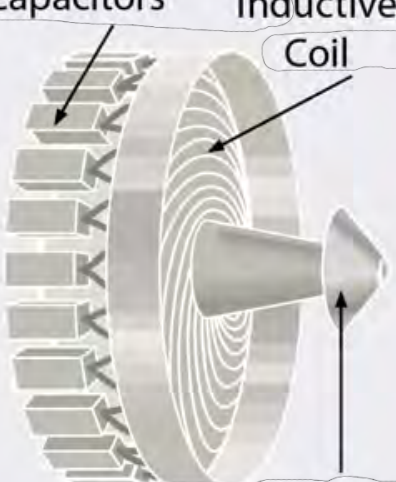

Propellant Nozzle
Inductive

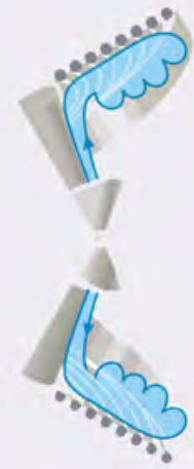

Ionization \& Acceleration

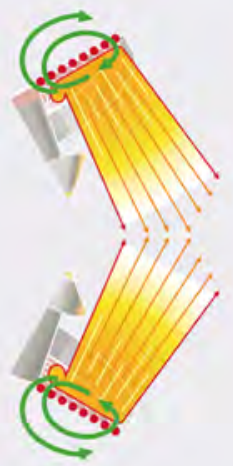

Propellant Injection 


\section{Circuit Model Still Applicable?}
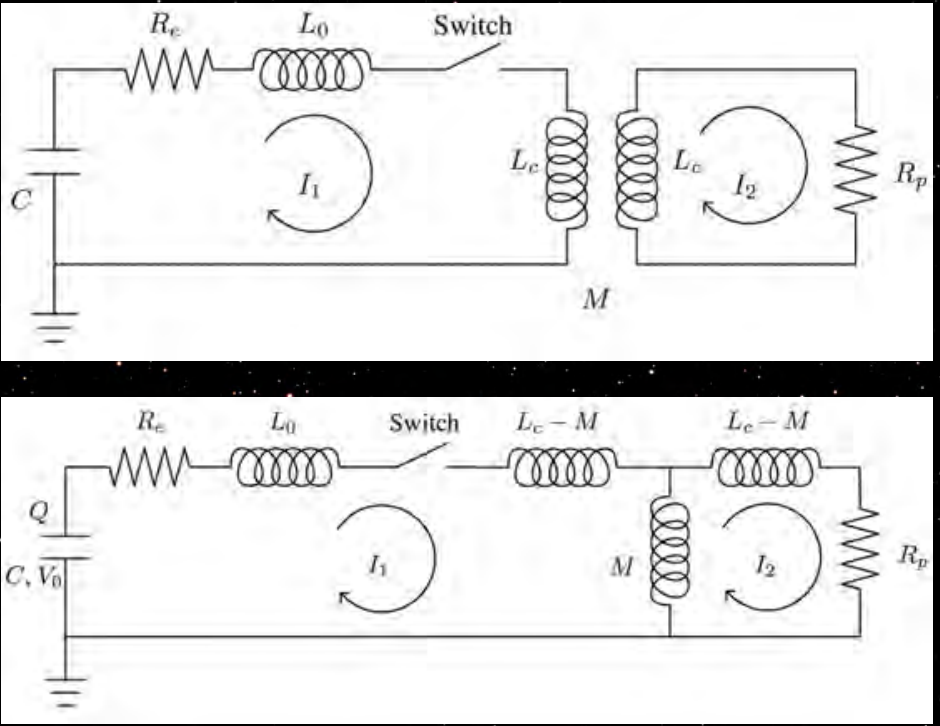


\section{Circuit Model Still Applicable?}
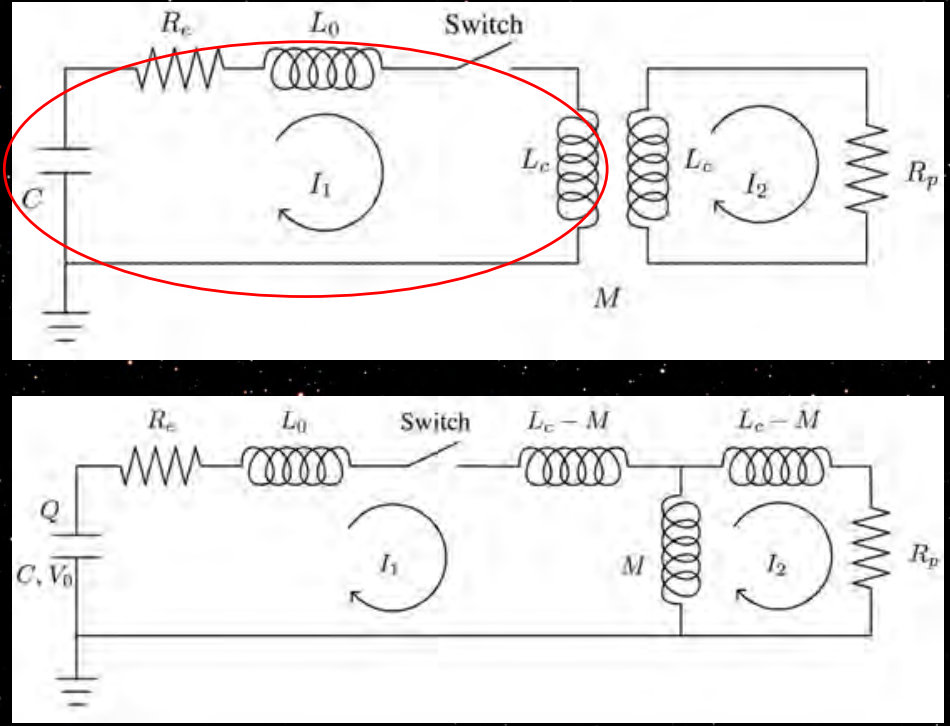


\section{Circuit Model Still Applicable?}
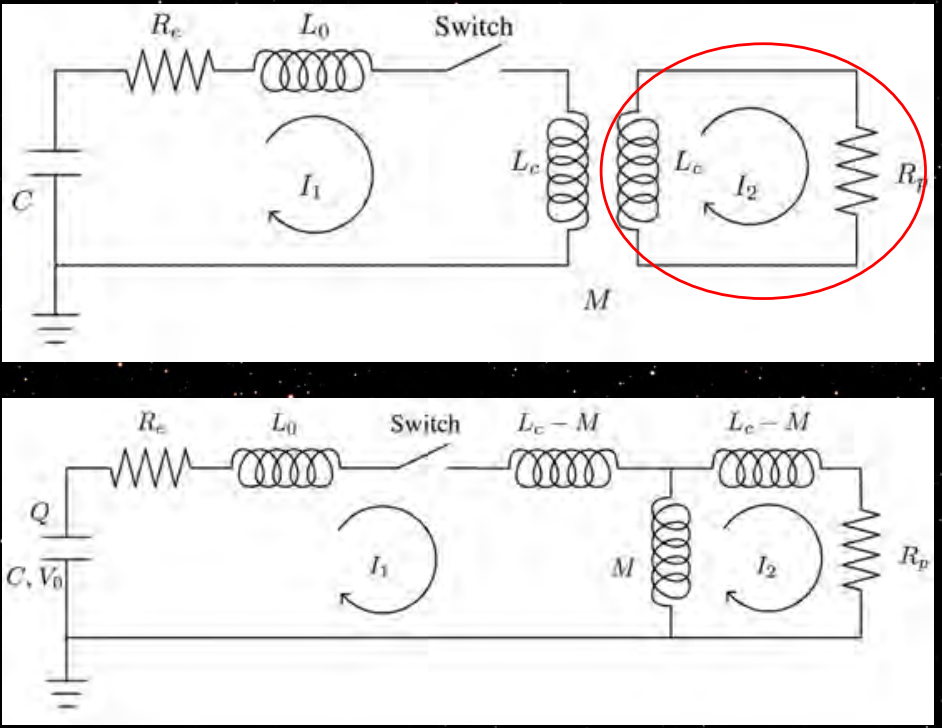


\section{Circuit Model Still Applicable?}
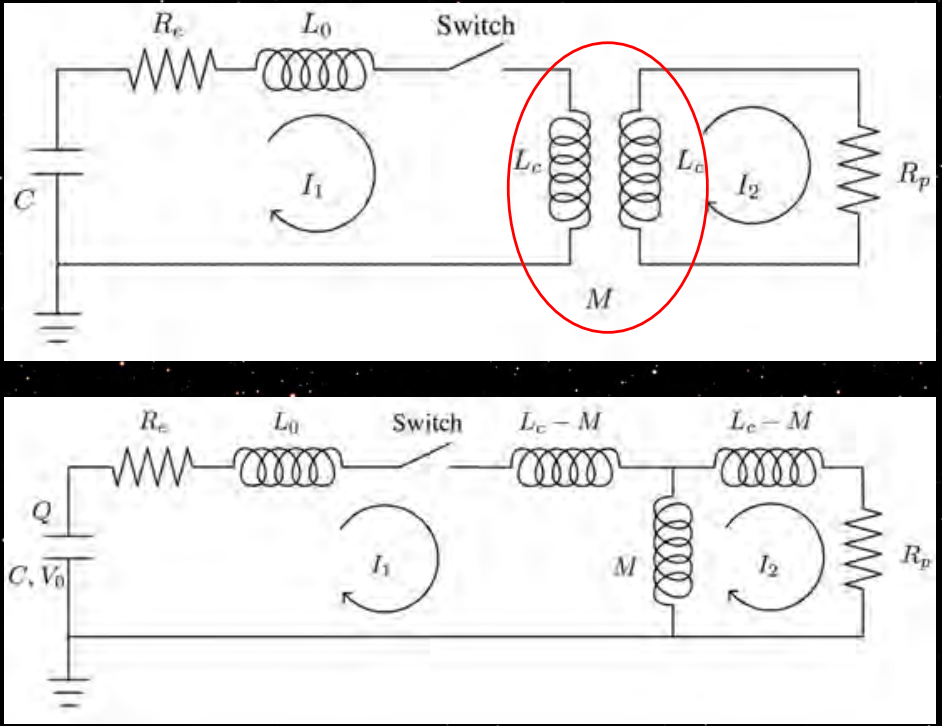


\section{Governing Equations via Kirchhoff's Law}

$$
\begin{gathered}
\frac{d l_{1}}{d t}=\frac{L_{C} V-L_{C} R_{e} I_{1}-M R_{p} I_{2}+\left(L_{C} l_{2}+M I_{1}\right) \frac{d M}{d t}}{L_{C}\left(L_{0}+L_{C}\right)-M^{2}} \\
\frac{d l_{2}}{d t}=\frac{M \frac{d l_{1}}{d t}+I_{1} \frac{d M}{d t}-R_{p} I_{2}}{L_{C}} \\
\quad \frac{d V}{d t}=-\frac{l_{1}}{C}
\end{gathered}
$$




\section{Definition of a Radial Location}

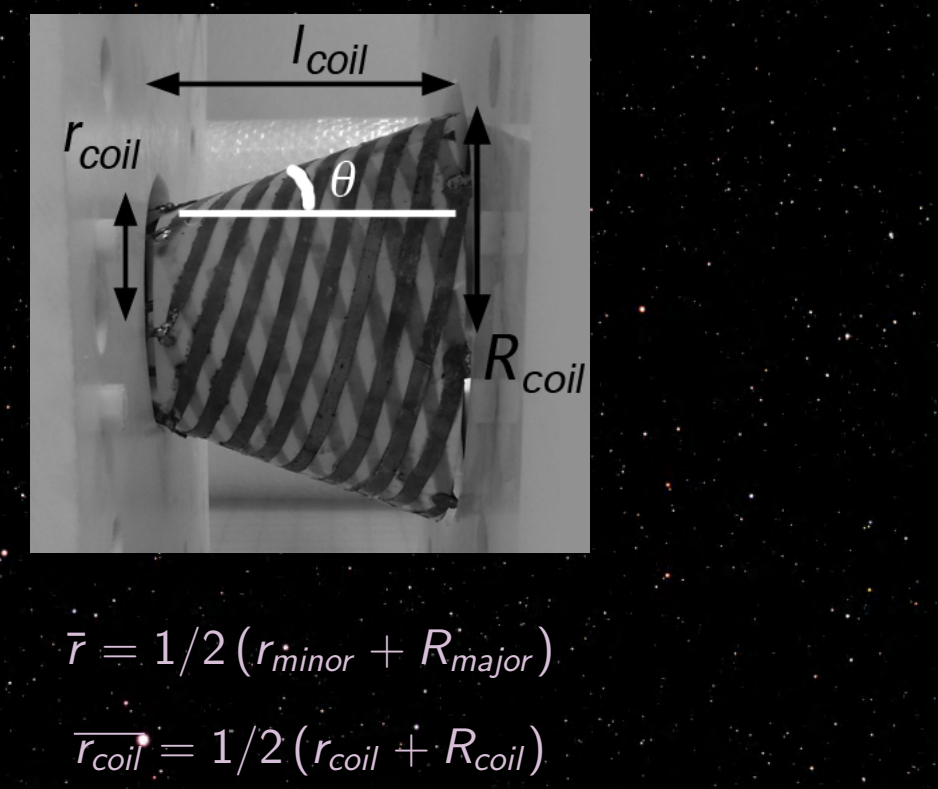




\section{2-D Equations Governing Current Sheet Coupling}

$$
\begin{gathered}
L_{\text {tot }}=L_{0}+L_{C}-\frac{M^{2}}{L_{C}} \\
L_{\text {tot }}(\bar{r}, z)=L_{0}+L_{C}\left(1-\exp \left(-z / z_{0}\right)\left(\frac{\bar{r}}{\overline{r_{\text {coil }}}}\right)^{N}\right) \\
M=L_{C} \exp \left(-\frac{z}{2 z_{0}}\right)\left(\frac{\bar{r}}{\overline{r_{\text {coil }}}}\right)^{N / 2} \\
\qquad \quad F_{i}=\frac{I^{2}}{2} \frac{\partial L}{\partial x_{i}}
\end{gathered}
$$




\section{2-D Equations Governing Current Sheet Coupling}

$$
\begin{gathered}
L_{t o t}=L_{0}+L_{C}-\frac{M^{2}}{L_{C}} \\
L_{t o t}(\bar{r}, z)=L_{0}+L_{C}\left(1-\exp \left(-z / z_{0}\right)\left(\frac{\bar{r}}{\overline{r_{\text {coil }}}}\right)^{N}\right) \\
M=L_{C} \exp \left(-\frac{z}{2 z_{0}}\right)\left(\frac{\bar{r}}{r_{\text {coil }}}\right)^{N / 2} \\
\cdot F_{i}=\frac{I^{2}}{2} \frac{\partial L}{\partial x_{i}}
\end{gathered}
$$




\section{2-D Equations Governing Current Sheet Coupling}

$$
\begin{gathered}
\text { Circuit Eqns. } L_{\text {tot }}=L_{0}+L_{C}-\frac{M^{2}}{L_{C}} \\
L_{\text {tot }}(\bar{r}, z)=L_{0}+L_{C}\left(1-\exp \left(-z / z_{0}\right)\left(\frac{\bar{r}}{\overline{r_{c o i l}}}\right)^{N}\right) \\
M=L_{C} \exp \left(-\frac{z}{2 z_{0}}\right)\left(\frac{\bar{r}}{r_{\text {coil }}}\right)^{N / 2} \\
\quad F_{i}=\frac{I^{2}}{2} \frac{\partial L}{\partial x_{i}}
\end{gathered}
$$




\section{2-D Equations Governing Current Sheet Coupling}

$$
\begin{gathered}
L_{\text {tot }}=L_{0}+L_{C}-\frac{M^{2}}{L_{C}} \\
L_{\text {tot }}(\bar{r}, z)=L_{0}+L_{C}\left(1-\exp \left(-z / z_{0}\right)\left(\frac{\bar{r}}{\overline{r_{\text {coil }}}}\right)^{N}\right) \\
M=L_{C} \exp \left(-\frac{z}{2 z_{0}}\right)\left(\frac{\bar{r}}{\bar{r}_{\text {coil }}}\right)^{N / 2} \\
\quad F_{i}=\frac{l^{2}}{2} \frac{\partial L}{\partial x_{i}}
\end{gathered}
$$




\section{2-D Equations Governing Current Sheet Coupling}

$$
\begin{gathered}
L_{\text {tot }}=L_{0}+L_{C}-\frac{M^{2}}{L_{C}} \\
L_{\text {tot }}(\bar{r}, z)=L_{0}+L_{C}\left(1-\exp \left(-z / z_{0}\right)\left(\frac{\bar{r}}{\overline{r_{\text {coil }}}}\right)^{N}\right) \\
M=L_{C} \exp \left(-\frac{z}{2 z_{0}}\right)\left(\frac{\bar{r}}{\overline{r_{\text {coil }}}}\right)^{N / 2} \text { Enpirical } \\
\quad F_{i}=\frac{I^{2}}{2} \frac{\partial L}{\partial x_{i}}
\end{gathered}
$$




\section{2-D Equations Governing Current Sheet Coupling}

$$
\begin{gathered}
L_{\text {tot }}=L_{0}+L_{C}-\frac{M^{2}}{L_{C}} \\
L_{\text {tot }}(\bar{r}, z)=L_{0}+L_{C}\left(1-\exp \left(-z / z_{0}\right)\left(\frac{\bar{r}}{\overline{r_{\text {coil }}}}\right)^{N}\right) \\
M=L_{C} \exp \left(-\frac{z}{2 z_{0}}\right)\left(\frac{\bar{r}}{r_{\text {coil }}}\right)^{N / 2} \\
\quad F_{i}=\frac{I^{2}}{2} \frac{\partial L}{\partial x_{i}}
\end{gathered}
$$




\section{2-D Equations Governing Current Sheet Coupling}

$$
\begin{gathered}
L_{C}-\frac{M^{2}}{L_{C}} \\
L_{C}\left(1-\exp \left(-z / z_{0}\right)\left(\frac{\bar{r}}{\overline{r_{\text {coil }}}}\right)^{N}\right)
\end{gathered}
$$$$
M=L_{C} \exp \left(-\frac{z}{2 z_{0}}\right)\left(\frac{\bar{r}}{\overline{r_{\text {coil }}}}\right)^{N / 2}
$$$$
F_{i}=\frac{I^{2}}{2} \frac{\partial L}{\partial x_{i}}
$$ 


\section{2-D Equations Governing Current Sheet Coupling}

$$
\begin{aligned}
& L_{\text {tot }}-L_{0}+L_{C}-\frac{M^{2}}{L_{C}} \text {. } \\
& L_{C}\left(1-\exp \left(-z / z_{0}\right)\left(\frac{\bar{r}}{\overline{r_{\text {coil }}}}\right)^{N}\right) \\
& =L_{C} \exp \left(-\frac{z}{2 z_{0}}\right)\left(\frac{\bar{r}}{\overline{r_{\text {coil }}}}\right)^{N / 2} \\
& F_{i}=\frac{I^{2}}{2} \frac{\partial L}{\partial x_{i}}
\end{aligned}
$$




\section{2-D Equations Governing Current Sheet Coupling}

$$
\begin{gathered}
L_{t o t}=L_{0}+L_{C}-\frac{M^{2}}{L_{C}} \\
L_{t o t}(\bar{r}, z)=L_{0}+L_{C}\left(1-\exp \left(-z / z_{0}\right)\left(\frac{\bar{r}}{\overline{r_{\text {coil }}}}\right)^{N}\right) \\
\quad M=L_{C} \exp \left(-\frac{z}{2 z_{0}}\right)\left(\frac{\bar{r}}{r_{\text {coil }}}\right)^{N / 2} \\
\quad \cdot \quad F_{i}=\frac{I^{2}}{2} \frac{\partial L}{\partial x_{i}}
\end{gathered}
$$




\section{2-D Equations Governing Current Sheet Coupling}

$$
\begin{gathered}
L_{\text {tot }}=L_{0}+L_{C}-\frac{M^{2}}{L_{C}} \\
L_{\text {tot }}(\bar{r}, z)=L_{0}+L_{C}\left(1-\exp \left(-z / z_{0}\right)\left(\frac{\bar{r}}{\overline{r_{\text {coil }}}}\right)^{N}\right) \\
M=L_{C} \exp \left(-\frac{z^{\prime}}{2 z_{0}}\right)\left(\frac{\bar{r}_{C}}{r_{\text {coil }}}\right)^{N / 2} \\
\\
\qquad F_{i}=\frac{I^{2}}{2} \frac{\partial L}{\partial x_{i}}
\end{gathered}
$$




\section{2-D Equations Governing Current Sheet Coupling}

$$
\begin{gathered}
L_{\text {tot }}=L_{0}+L_{C}-\frac{M^{2}}{L_{C}} \\
L_{\text {tot }}(\bar{r}, z)=L_{0}+L_{C}\left(1-\exp \left(-z / z_{0}\right)\left(\frac{\bar{r}}{\overline{r_{\text {coil }}}}\right)^{N}\right) \\
M=L_{C} \exp \left(-\frac{z}{2 z_{0}}\right)\left(\frac{\bar{r}}{\frac{r_{\text {coil }}}{}}\right)^{N / 2} \\
\\
\qquad F_{i}=\frac{I^{2}}{2} \frac{\partial L}{\partial x_{i}}
\end{gathered}
$$




\section{2-D Equations Governing Current Sheet Coupling}

$$
\begin{gathered}
L_{\text {tot }}=L_{0}+L_{C}-\frac{M^{2}}{L_{C}} \\
L_{\text {tot }}(\bar{r}, z)=L_{0}+L_{C}\left(1-\exp \left(-z / z_{0}\right)\left(\frac{\bar{r}}{\overline{r_{\text {coil }}}}\right)^{N}\right) \\
M=L_{C} \exp \left(-\frac{z}{2 z_{0}}\right)\left(\frac{\bar{r}}{\frac{r_{\text {coil }}}{}}\right)^{N / 2} \\
\\
\qquad F_{i}=\frac{I^{2}}{2} \frac{\partial L}{\partial x_{i}}
\end{gathered}
$$




\section{Equations Governing Current Sheet Motion}

$$
\begin{gathered}
\left.\frac{d v_{z}}{d t}=\frac{\left[\frac{L C l_{1}^{2}}{2 z_{0}} \exp \left(-\frac{z}{z_{0}}\right)\left(\frac{\bar{r}}{r_{c o i l}}\right)^{N}\right]}{m_{\text {bit }}}\right] \\
\frac{d v_{r}}{d t}=\frac{\left[P_{2} 2 \pi \bar{r} I_{c o i l}-\frac{L C l_{1}^{2} N}{2 r_{c o i l}} \exp \left(-\frac{z}{z_{0}}\right)(\bar{r})^{N-1}\right]}{m_{b i t}} \\
\therefore \quad \frac{P_{2}}{P_{\mathrm{r}}}=1+\frac{2 \gamma}{\gamma+1}\left[\mathcal{M}^{2}-1\right]
\end{gathered}
$$




\section{Equations Governing Current Sheet Motion}

$$
\begin{aligned}
& \frac{d v_{z}}{d t}=\frac{\left[\frac{L C l_{1}^{2}}{2 z_{0}} \exp \left(-\frac{z}{z_{0}}\right)\left(\frac{\bar{r}_{c}}{r_{\text {coil }}}\right)^{N} \cdot\right]}{m_{\text {bit }}} \\
& \frac{d v_{r}}{d t}=\frac{\left[P_{2} 2 \pi \bar{r} l_{c o i l}-\frac{L_{c} l_{1}^{2} N}{2 r_{c o i n} N} \exp \left(-\frac{z}{z_{0}}\right)(\bar{r})^{N-1}\right]}{m_{\text {bit }}} \\
& \frac{P_{2}}{P_{1}}=1+\frac{2 \gamma}{\gamma+1}\left[\mathcal{M}^{2}-1\right]
\end{aligned}
$$




\section{Equations Governing Current Sheet Motion}

$$
\begin{aligned}
& \frac{d v_{z}}{d t}=\frac{\left[\frac{L C_{1}^{2}}{2 z_{0}} \exp \left(-\frac{z}{z_{0}}\right) \cdot\left(\frac{\bar{T}_{c}}{\bar{r}_{\text {coil }}}\right)^{N}\right]}{m_{\text {bit }}} \\
& \frac{d v_{r}}{d t}=\frac{\left[P_{2} 2 \pi \bar{r} l_{c o i l}-\frac{L_{c} l_{1}^{2} N}{2 r_{c o i n} N} \exp \left(-\frac{z}{z_{0}}\right)(\bar{r})^{N-1}\right]}{m_{\text {bit }}} \\
& \frac{P_{2}}{P_{1}}=1+\frac{2 \gamma}{\gamma+1}\left[\mathcal{M}^{2}-1\right]
\end{aligned}
$$




\section{Equations Governing Current Sheet Motion}

$$
\begin{gathered}
\frac{d v_{z}}{d t}=\frac{\left[\frac{L C l_{1}^{2}}{2 z_{0}} \exp \left(-\frac{z}{z_{0}}\right)\left(\frac{\bar{r}}{\bar{r}_{c o i l}}\right)^{N}\right]}{m_{\text {bit }}} \\
\frac{d v_{r}}{d t}=\frac{\left[P_{2} 2 \pi \bar{r} I_{c o i l}-\frac{L C l_{1}^{2} N}{2 r_{c o i l}} \exp \left(-\frac{z}{z_{0}}\right)(\bar{r})^{N-1}\right]}{m_{\text {bit }}} \\
\therefore \frac{P_{2}}{P_{1}}=1+\frac{2 \gamma}{\gamma+1}\left[\mathcal{M}^{2}-1\right]
\end{gathered}
$$




\section{Equations Governing Current Sheet Motion}

$$
\begin{aligned}
& \frac{d v_{z}}{d t}=\frac{\left[\frac{L C l_{1}^{2}}{2 z_{0}} \exp \left(-\frac{z}{z_{0}}\right)\left(\frac{\Gamma}{r_{c o i l}}\right)^{N}\right]}{m_{\text {bit }}} \\
& \frac{d v_{r}}{d t}=\frac{\left[P_{2} 2 \pi \bar{r} l_{c o i l}-\frac{L_{c} l_{1}^{2} N}{2 r_{c o i l} N} \exp \left(-\frac{z}{z_{0}}\right)(\bar{r})^{N-1}\right]}{m_{\text {bit }}} \\
& \frac{P_{2}}{P_{1}}=1+\frac{2 \gamma}{\gamma+1}\left[\mathcal{M}^{2}-1\right]
\end{aligned}
$$




\section{Equations Governing Current Sheet Motion}

$$
\begin{aligned}
& \frac{d v_{z}}{d t}=\frac{\left[\frac{L C l_{1}^{2}}{2 z_{0}} \exp \left(-\frac{z}{z_{0}}\right)\left(\frac{r_{r}}{r_{c o i l}}\right)^{N}\right]}{m_{\text {bit }}} \\
& \frac{d v_{r}}{d t}=\frac{\left[\left.P_{2} 2 \pi \bar{r}\right|_{c o j l}-\frac{L_{c} l_{1}^{2} N}{2 F_{c o i n} N} \exp \left(-\frac{z}{z_{0}}\right)(\bar{r})^{N-1}\right]}{m_{\text {bit }}} \\
& \frac{P_{2}}{P_{1}}=1+\frac{2 \gamma}{\gamma+1}\left[\mathcal{M}^{2}-1\right]
\end{aligned}
$$




\section{Equations Governing Current Sheet Motion}

$$
\frac{d v_{z}}{d t}=\frac{\left[\frac{L_{C} l_{1}^{2}}{2 z_{0}} \exp \left(-\frac{z}{z_{0}}\right)\left(\frac{\bar{r}}{\overline{r_{\text {coil }}}}\right)^{N}\right]}{m_{\text {bit }}}
$$

$$
\frac{d v_{r}}{d t}=\frac{\left[\left.P_{2} 2 \pi \bar{k}\right|_{c o l l}-\frac{L_{c} l_{1}^{2} N}{2 r_{c o i l}} \exp \left(-\frac{z}{z_{0}}\right)(\bar{r})^{N-1}\right]}{m_{\text {bit }}}
$$




\section{Model Results}
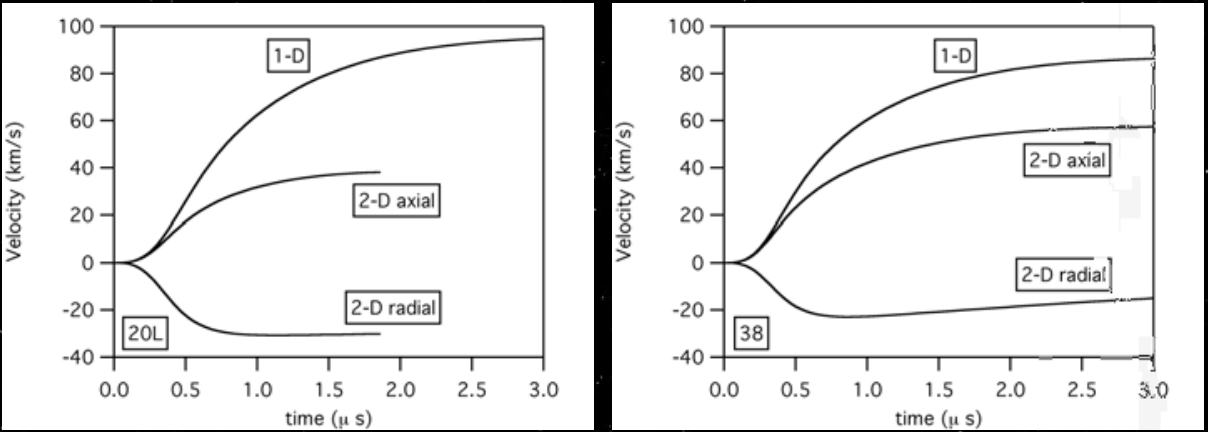
Radial Motion Accelerates Decoupling and Decreases Energy Transferred

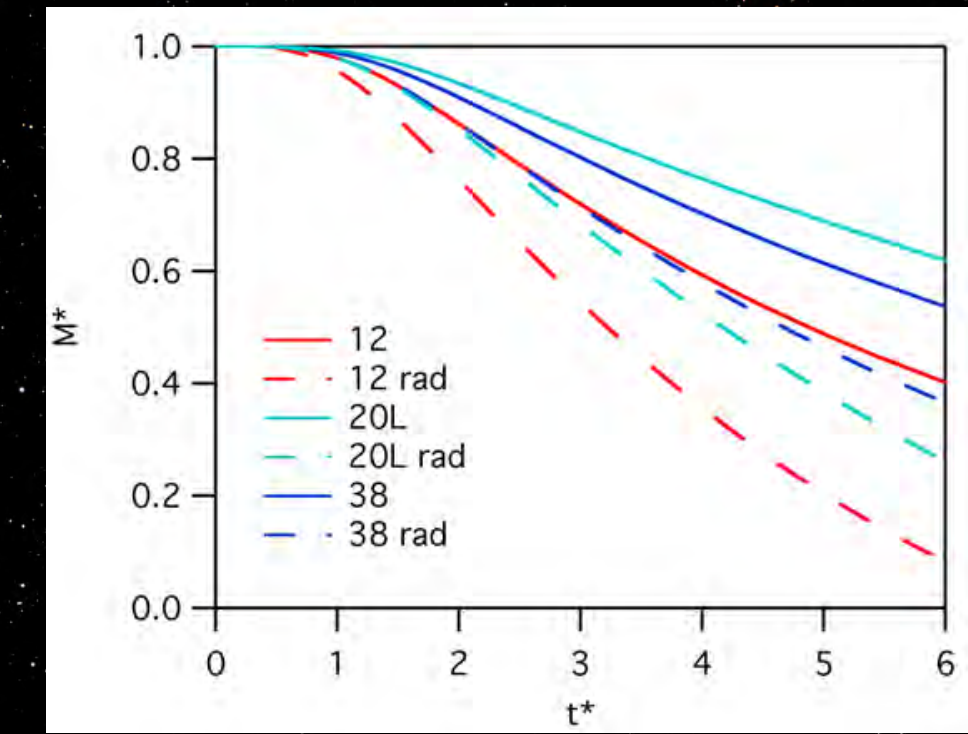


Experiment 
Conical Inductive Coil for Increased Propellant Utilization Efficiency

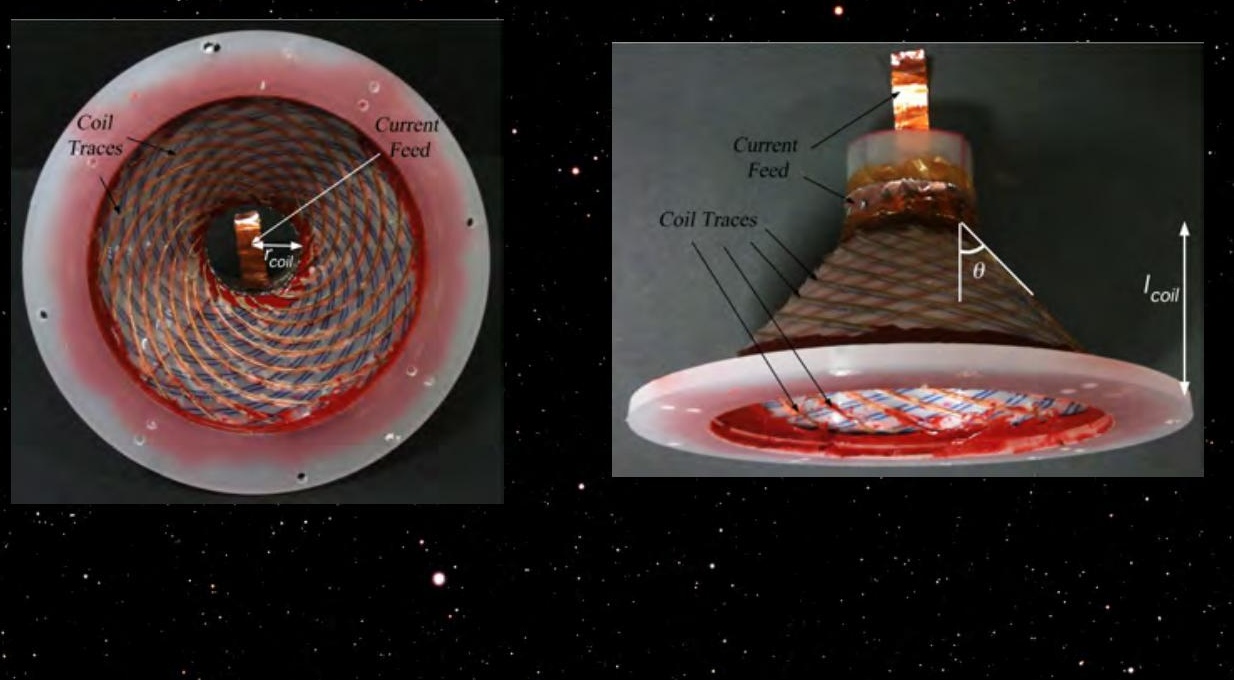




\section{Preionizer}
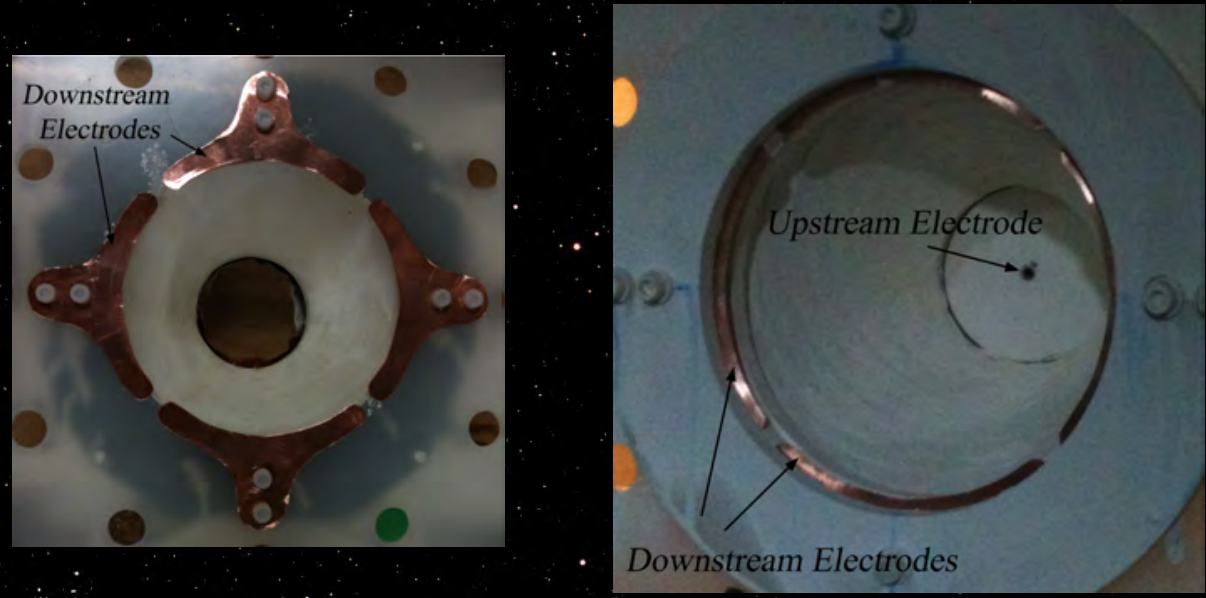
Preionizer 


\section{Highly Sensitive Hanging Pendulum Thrust Stand}
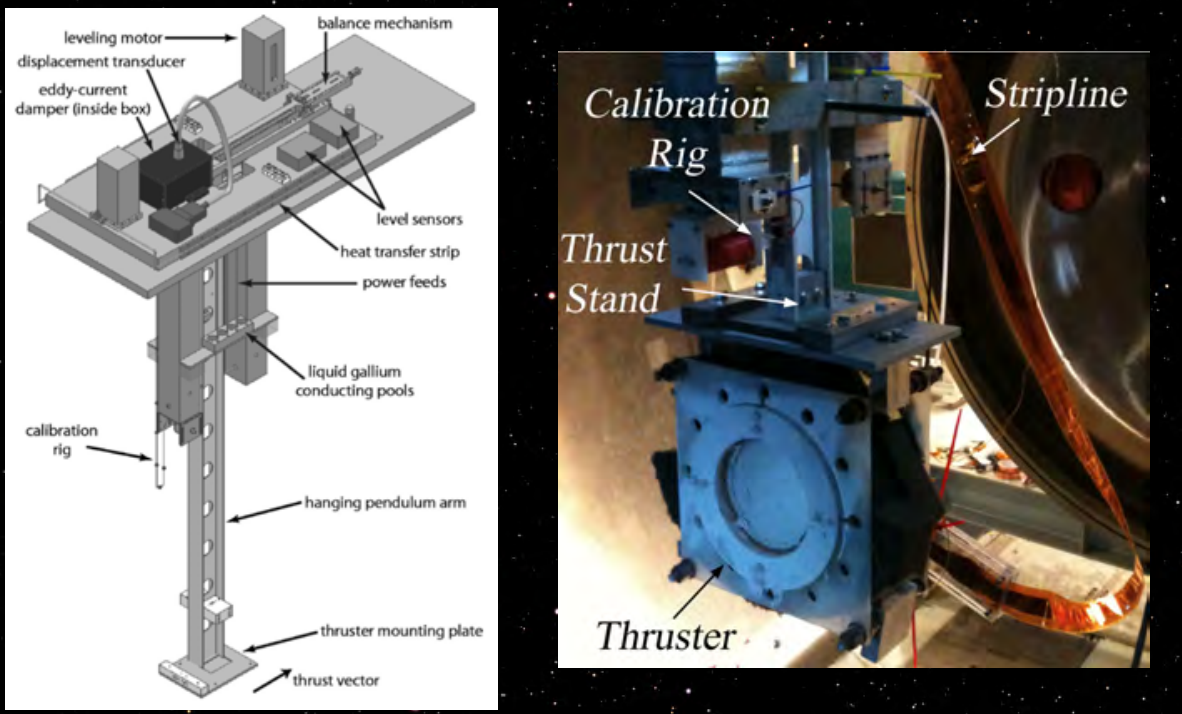


\section{Contactless Thrust Stand Calibration}
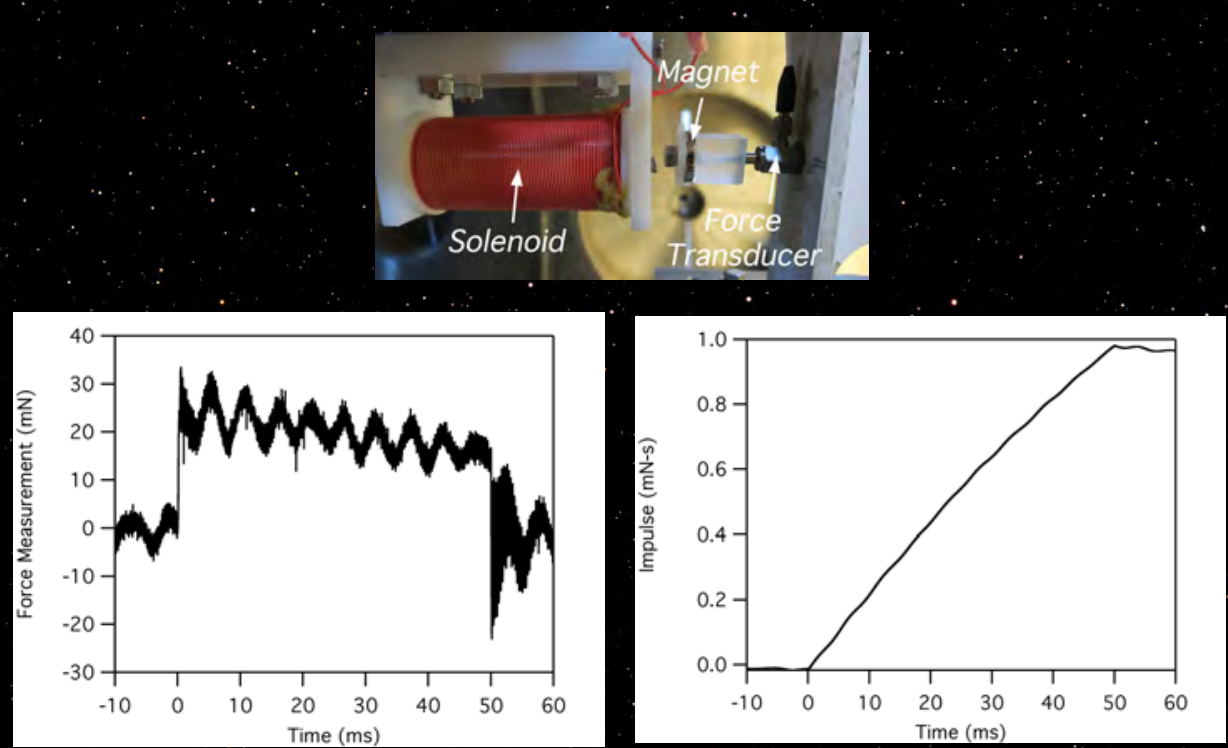


\section{Arm Dynamics. Modeled as Spring-Mass-Damper}
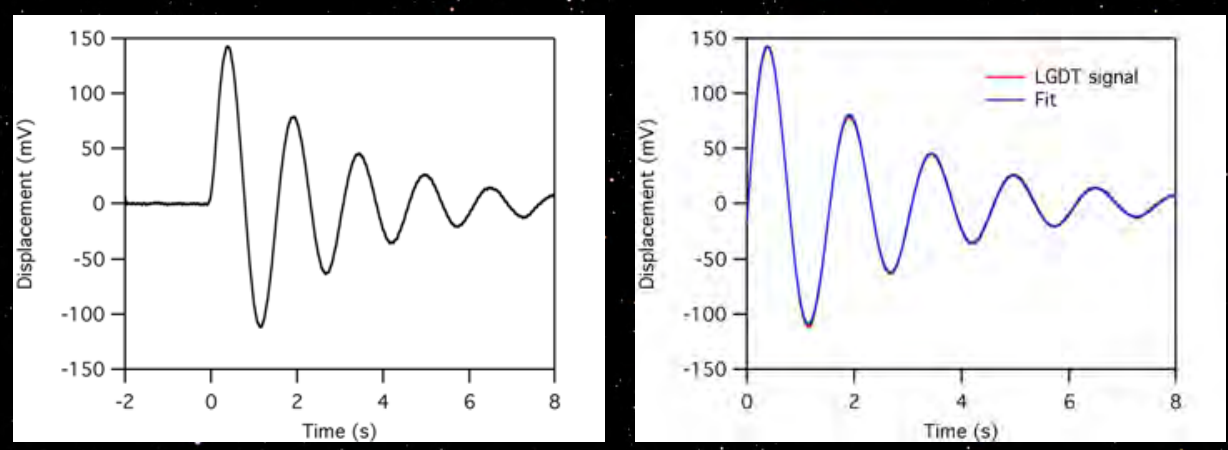


\section{Thrust Stand Calibration Curve}

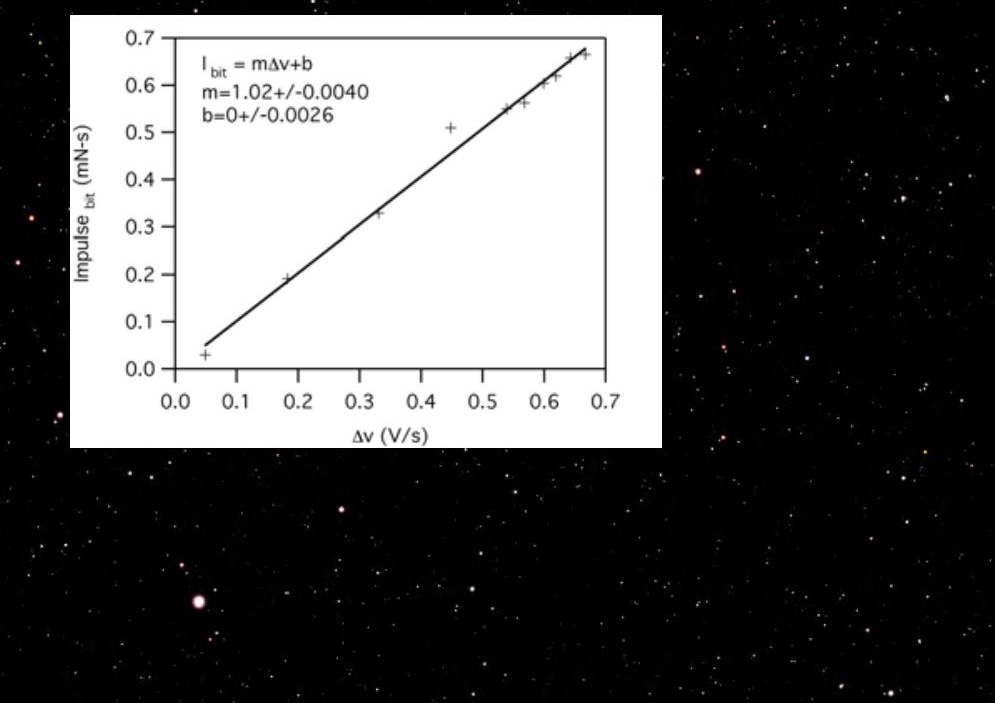


Experimental Results: Impulse Measurements 
Impulse Bit Measurements for $20^{\circ}$ (argon)
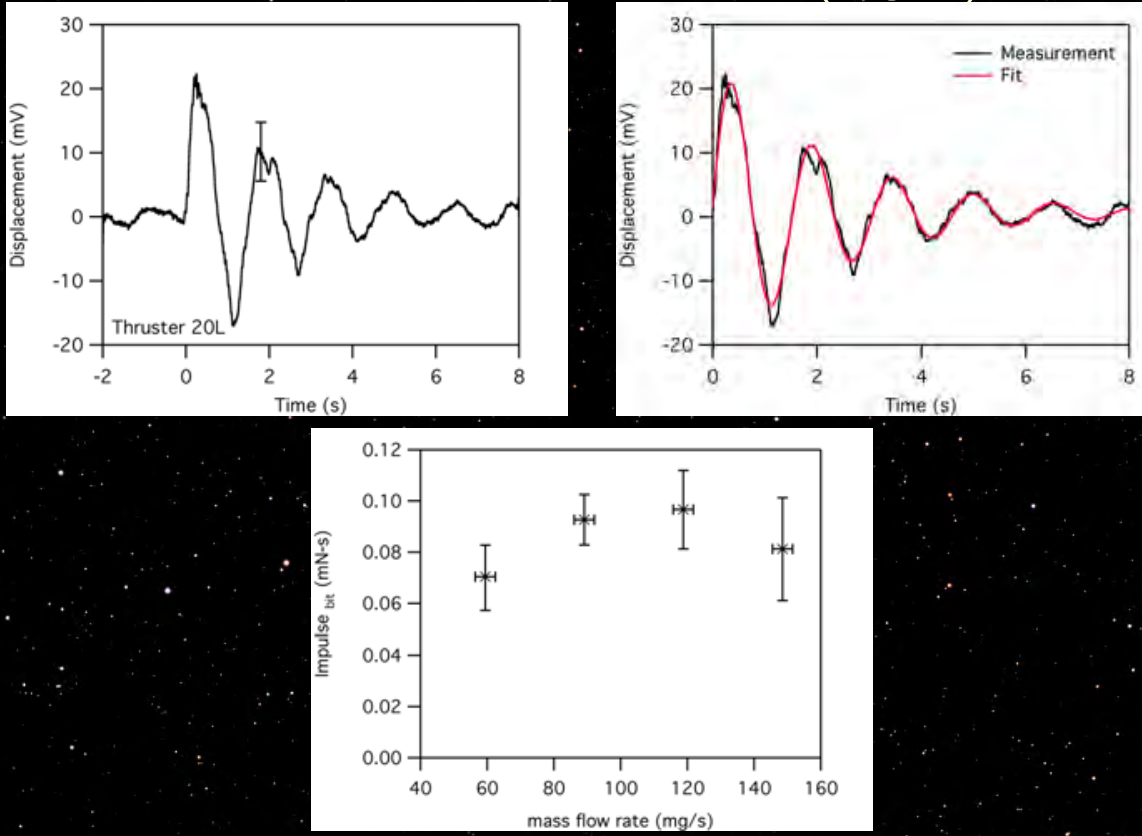


\section{Experimental Results: Time-integrated Photographs}


Varying Capacitor Voltage with $20^{\circ}$
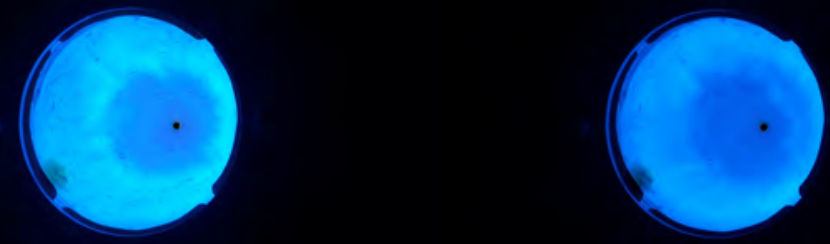
Varying mass flow rate with $20^{\circ}$
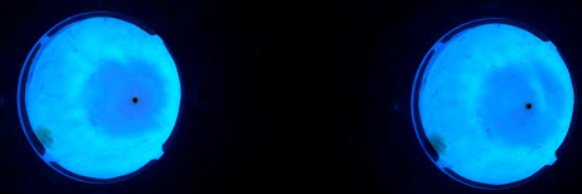
Varying mass flow rate with $38^{\circ}$ 


\section{Comparison of $20^{\circ}$ and $38^{\circ}$}
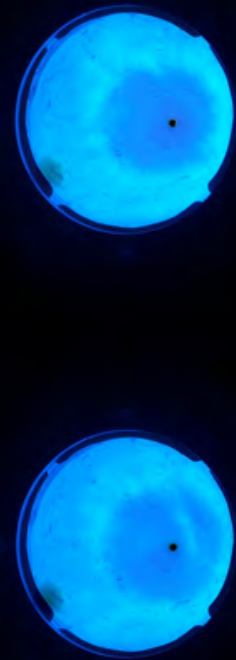


\section{Discussion of Experimental Results}


Previous analytical results suggest radial motion is detrimental to thrust
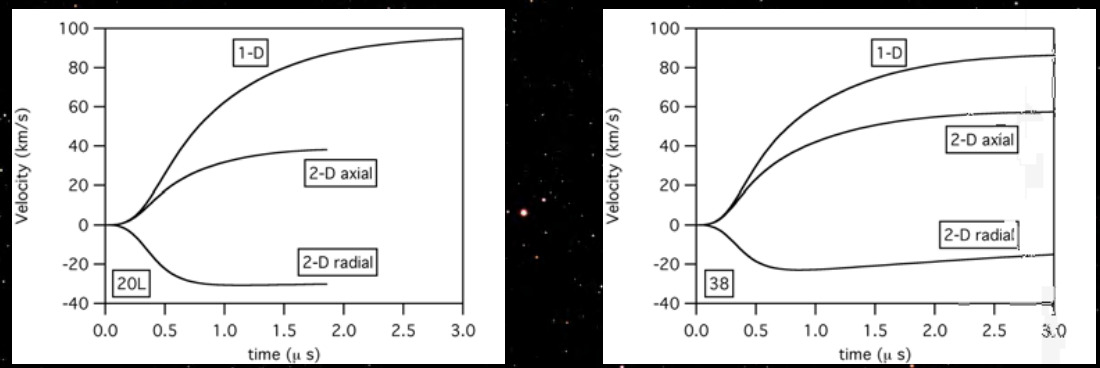

Model assưmptions: magnetically impermeable current sheet, no conversion from radial motion to axial motion

Result: Coil with narrower angle produced higher thrust 
Closer look at decreasing mass flow rate for $20^{\circ}$

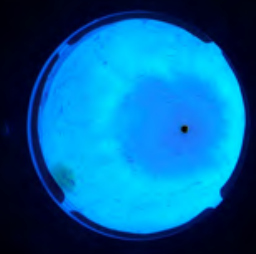


Decreasing mass flow rate vs. voltage for $20^{\circ}$ 


\section{Conclusions}




\section{Conclusions}

Thruster with narrower coil produces more thrust Model results suggest the opposite would occur Refinement of model or experiment or both is warranted

Simplicity of model has advantages. Propellant injection may be a good starting point 
Questions? 